\title{
Electromechanical interaction in rotordynamics of cage induction motors
}

\author{
Timo P. Holopainen \\ VTT Industrial Systems
}

Dissertation for the degree of Doctor of Science in Technology to be presented with due permission of the Department of Electrical and Communications Engineering for public examination and debate in Auditorium S4 at Helsinki University of Technology (Espoo, Finland), on the 24th of August, 2004, at 12 noon. 
ISBN 951-38-6404-9 (soft back ed.)

ISSN 1235-0621 (soft back ed.)

ISBN 951-38-6405-7 (URL: http://www.vtt.fi/inf/pdf/; URL: http://lib.hut.fi/Diss/)

ISSN 1455-0849 (URL: http://www.vtt.fi/inf/pdf/; URL: http://lib.hut.fi/Diss/)

Copyright $(C$ VTT Technical Research Centre of Finland 2004

JULKAISIJA - UTGIVARE - PUBLISHER

VTT, Vuorimiehentie 5, PL 2000, 02044 VTT

puh. vaihde (09) 4561, faksi (09) 4564374

VTT, Bergsmansvägen 5, PB 2000, 02044 VTT

tel. växel (09) 4561, fax (09) 4564374

VTT Technical Research Centre of Finland, Vuorimiehentie 5, P.O.Box 2000, FIN-02044 VTT, Finland phone internat. +35894561 , fax +35894564374

VTT Tuotteet ja tuotanto, Otakaari 7 B, PL 13022, 02044 VTT

puh. vaihde (09) 4561, faksi (09) 4566475

VTT Industriella System, Otsvängen 7 B, PB 13022, 02044 VTT

tel. växel (09) 4561, fax (09) 4566475

VTT Industrial Systems, Otakaari 7 B, P.O.Box 13022, FIN-02044 VTT, Finland

phone internat. +35894561 , fax +35894566475

Technical editing Leena Ukskoski

Otamedia Oy, Espoo 2004 
Holopainen, Timo P. Electromechanical interaction in rotordynamics of cage induction motors. Espoo 2004. VTT Publications 543. 64 p. + app. 81 p.

Keywords unbalanced magnetic pull, electromechanical interaction, rotors, electric motors, vibration characteristics

\section{Abstract}

Electromagnetic fields in the air gap of an electric machine produce electromagnetic forces between the rotor and stator. The total force exerted on the rotor due to the eccentric rotor position is called the unbalanced magnetic pull. This eccentricity force is directed roughly over the shortest air gap. At low frequencies, the vibration amplitudes of flexural modes may be large enough to couple the electromagnetic system to the mechanical one. This electromechanical interaction changes the vibration behaviour of the system.

The main purpose of this dissertation is to reveal the main rotordynamic consequences induced by the electromechanical interaction in cage induction motors. Another goal is to achieve this by deriving a simple and representative electromechanical rotor model with physical variables and parameters.

In this study, a new parametric model was derived for the unbalanced magnetic pull induced by an arbitrary rotor motion in transient operation. The parameters of this model can be determined analytically from the basis of the machine characteristics or estimated numerically as in this study. To estimate the parameters, an efficient numerical method was developed from the analysis of impulse response. The numerical results showed that the simple electromagnetic force model, together with the estimated parameters, predicts the unbalanced magnetic pull fairly accurately.

An electromechanical rotor model was derived by combining the Jeffcott rotor model with the simple electromagnetic force model, including two additional variables for the harmonic currents of the rotor cage. Applying this model, the rotordynamic effects of electromechanical interaction were studied. Three induction motors were used in the numerical examples. The results obtained show that the electromechanical interaction may decrease the flexural frequen- 
cies of the rotor, induce additional damping or cause rotordynamic instability. These interaction effects are most significant in motors operating at, or near, the first flexural critical speed. Excluding the potential rotordynamic instability, the numerical results indicate that the electromechanical interaction effectively reduces the unbalance response close to the first flexural critical speed. 


\section{Preface}

This work was carried out during the period 2001-2003 as a part of the research project "Electromechanical interaction in vibration control of electric machines". The aim of this project was to enhance our understanding of the effects of electromechanical interaction in general, and electromagnetic damping in particular, on the vibration control of electrical machines. The research partners were the Laboratory of Electromechanics at Helsinki University of Technology (HUT), and VTT Industrial Systems. The project was financed by the National Technology Agency of Finland (Tekes), ABB Oy, Fortum Power and Heat Oy, High Speed Tech Oy Ltd, Sundyne Ltd, and the research partners.

I am greatly indebted to Professor Antero Arkkio, Laboratory of Electromechanics, who supervised and advised me during the thesis, for his invaluable help and encouragement. I worked in close cooperation with Dr Asmo Tenhunen, Laboratory of Electromechanics. I thank him for frequent fruitful discussions, which raised several ideas included in this work. I am grateful to Dr Erkki Lantto, High Speed Tech Oy, for his continuous support and help. This study benefited greatly from his extensive experience and expertise in the dynamics of electric machines. I express my gratitude to Professor Mauri Määttänen, Laboratory for Mechanics of Materials (HUT), for his useful comments, suggestions and encouragement through the course of many years. I would like to thank Dr Seppo Aatola, VTT Industrial Systems, for his great help in the application of spectral analysis techniques. I thank Mr Paul Klinge, VTT Industrial Systems, for his useful discussions and comments, and for his kind help and cooperation over many years. I express my gratitude to Emeritus Professor Tapani Jokinen, Laboratory of Electromechanics, for his invaluable comments, suggestions and encouragement. I am grateful to Mr Pekka Koskinen, VTT Industrial Systems, for useful discussions and background arrangements. The management group of the above-mentioned Tekes-project supported the research work and gave fruitful feedback from the industrial point of view. I gratefully acknowledge this help and hope that this dissertation brings added value for the industrial partners.

During this research project, I was a visiting researcher at the Laboratory of Electromechanics. I would like to express my gratitude to all the laboratory members for their helpful discussions with me, as well as the creative exchange of ideas and friendly atmosphere. I am indebted to the members of my own 
research group, Rotating Machines, VTT Industrial Systems, for their kind help, diverse ways of support and continuous encouragement during this work.

The financial support of Tekniikan Edistämissäätiö (Foundation of Technology in Finland) is gratefully acknowledged.

Finally, I would like to thank my wife, Susann, and our children, Niklas, Elsa and Peik, for their encouragement and patience during this work.

Espoo, June 2004 


\section{Contents}

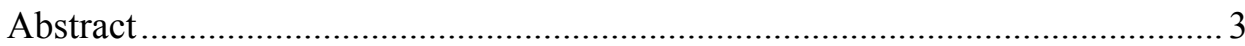

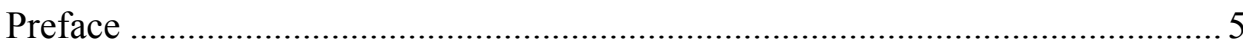

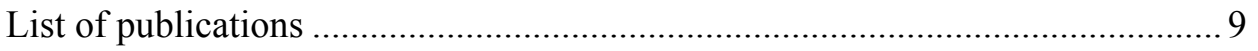

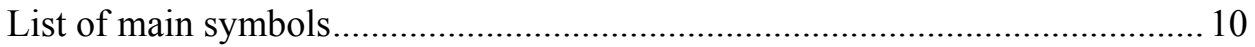

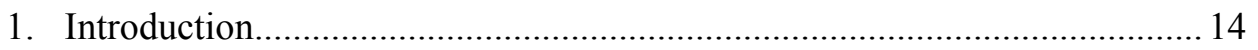

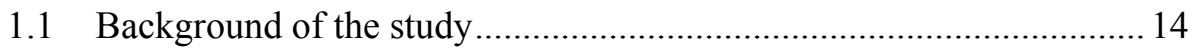

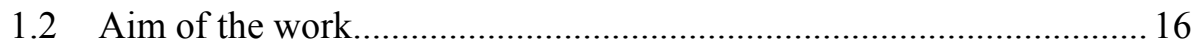

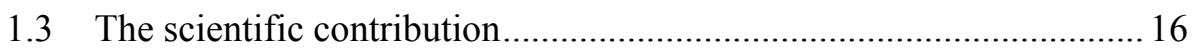

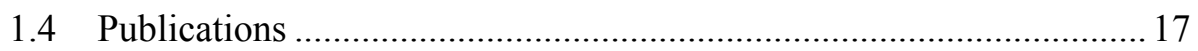

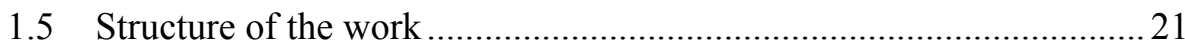

2. Overview of the electromechanical interaction in rotordynamics ................22

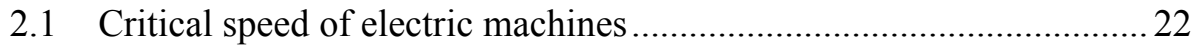

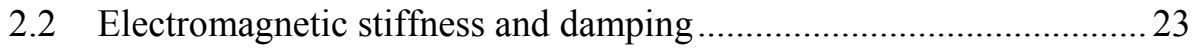

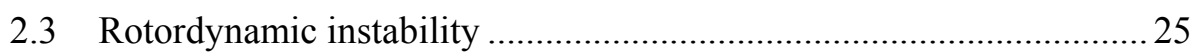

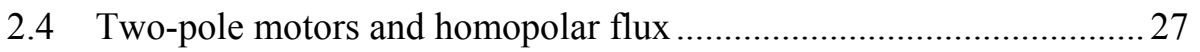

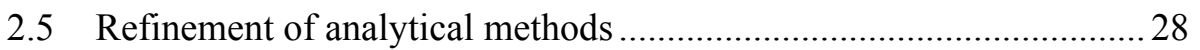

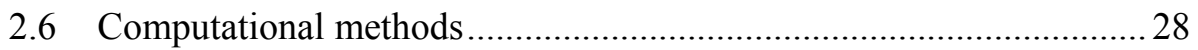

2.7 Experimental studies on cage-rotor vibrations ................................... 30

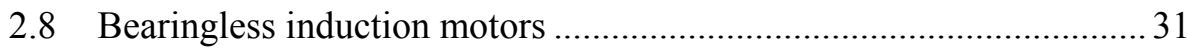

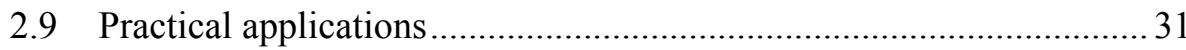

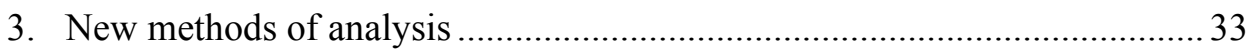

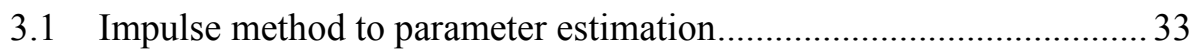

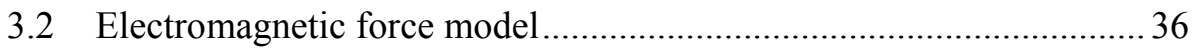

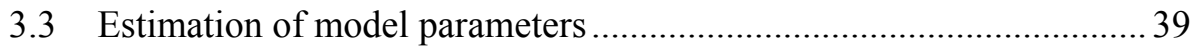

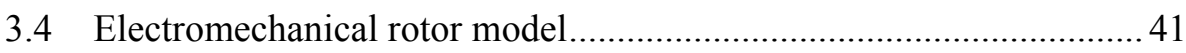

3.5 Verification of the electromagnetic force and electromechanical rotor model 


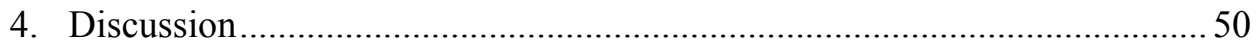

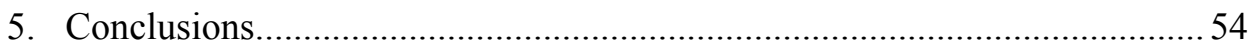

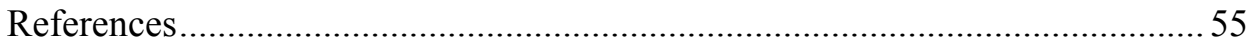

\section{Appendices I-VI \\ Publications P1-P6}

Appendices III-VI of this publication are not included in the PDF version.

Please order the printed version to get the complete publication

(http://www.vtt.fi/inf/pdf/) 


\section{List of publications (Appendices I-VI)}

P1. Holopainen, T. P., Tenhunen, A. \& Arkkio, A. 2002. Electromagnetic Circulatory Forces and Rotordynamic Instability in Electric Machines. In: Hahn, E. J. \& Randall, R. B. (eds.). Proceedings of the 6th International Conference on Rotor Dynamics. Sydney, Australia, 30.9-4.10, 2002. Vol. 1. Sydney: University of New South Wales Printing Services. Pp. 446-463. ISBN 0-7344-1963-1

P2. Holopainen, T. P., Tenhunen, A. \& Arkkio, A. 2002. Electromechanical Interaction in Rotor Vibrations of Electric Machines. In: Mang, H. A., Rammerstorfer, F. G. \& Eberhardsteiner, J. (eds.). Proceedings of the 5th World Congress on Computational Mechanics. Vienna, Austria, 7-12 July, 2002. Vienna: Vienna University of Technology. $10 \mathrm{p}$. Available: http://wccm.tuwien.ac.at.

P3. Holopainen, T. P., Tenhunen, A., Lantto, E. \& Arkkio, A. 2004. Numerical identification of electromagnetic force parameters for linearized rotordynamic model of cage induction motors. Journal of Vibration and Acoustics, Vol. 126, Issue 3, pp. 384-390. ISSN 1528-8927

P4. Holopainen, T. P., Tenhunen, A., Lantto, E. \& Arkkio, A. Unbalanced magnetic pull induced by arbitrary eccentric motion of cage rotor in transient operation. Part 1: Analytical model. Electrical Engineering. In press. ISSN 0948-7921 (Paper) 1432-0487 (Online)

P5. Holopainen, T. P., Tenhunen, A., Lantto, E. \& Arkkio, A. Unbalanced magnetic pull induced by arbitrary eccentric motion of cage rotor in transient operation. Part 2: Verification and numerical parameter estimation. Electrical Engineering. In press. ISSN 0948-7921 (Paper) 1432-0487 (Online)

P6. Holopainen, T. P., Tenhunen, A. \& Arkkio, A. Electromechanical interaction in rotordynamics of cage induction motors. Journal of Sound and Vibration. In press. ISSN 0022-460X 


\title{
List of main symbols
}

\author{
including corresponding SI-units
}
$\underline{a} \quad$ unbalance vector, $[\mathrm{m}]$
$a_{p \pm 1}, a_{\mathrm{q}, p \pm 1}$ parameters related to different force models, [A/m]
$\underline{\hat{B}}_{\delta, p} \quad$ space vector for the magnetic flux density in the air gap; fundamental component, [T]

$B_{p} \quad$ amplitude for the magnetic flux density of fundamental component, [T]

$c_{p \pm 1} \quad$ force model parameters, [N/A]

$d \quad$ external viscous damping coefficient, $[\mathrm{N} \cdot \mathrm{s} / \mathrm{m}]$

$d_{\mathrm{e}} \quad$ electromagnetic damping coefficient, $[\mathrm{N} \cdot \mathrm{s} / \mathrm{m}]$

$d_{\mathrm{r}}, d_{\mathrm{s}} \quad$ outer diameter of the rotor; inner diameter of the stator, [m]

$\underline{F}_{\mathrm{e}} \quad$ electromagnetic total force exerted on the rotor, $[\mathrm{N}]$

$\underline{G} \quad$ frequency response function between the electromagnetic force and whirling radius, $[\mathrm{N} / \mathrm{m}]$

$\hat{\hat{i}}_{p \pm 1} \quad$ space-vector variables for cage-current components, [A]

$\underline{\hat{i}}_{\mathrm{r}, \nu}, \underline{\hat{i}}_{\mathrm{s}, \nu} \quad$ space-vector for harmonic rotor and stator current component $v$, [A]

$\hat{i}_{\mathrm{re}, p} \quad$ space-vector for fundamental component of equivalent rotor current, $[\mathrm{A}]$ 


\begin{tabular}{|c|c|}
\hline$k$ & shaft stiffness coefficient, $[\mathrm{N} / \mathrm{m}]$ \\
\hline$k_{\mathrm{e}}$ & electromagnetic stiffness coefficient, $[\mathrm{N} / \mathrm{m}]$ \\
\hline$k_{0}, k_{\mathrm{q} 0}$ & parameters related to different force models, $[\mathrm{N} / \mathrm{m}]$ \\
\hline$k_{p \pm 1}$ & coupling factors due to the leakage flux and saturation, [-] \\
\hline$\underline{k}_{p \pm 1}$ & force model parameters, $[\mathrm{N} \cdot \mathrm{rad} / \mathrm{m} \cdot \mathrm{s}]$ \\
\hline$L$ & self-inductance of one rotor-cage mesh, $[\mathrm{H}]$ \\
\hline$L_{\mathrm{m}, p}$ & magnetizing inductance of fundamental component, $[\mathrm{H}]$ \\
\hline$L_{\mathrm{r}, v}$ & rotor inductance of harmonic component $v,[\mathrm{H}]$ \\
\hline$L_{\mathrm{r \sigma}, p}, L_{\mathrm{s} \sigma, p}$ & $\begin{array}{l}\text { leakage inductance of rotor and stator for fundamental component, } \\
{[\mathrm{H}]}\end{array}$ \\
\hline$l, l_{\mathrm{e}}$ & overall length of the core; equivalent core length, $[\mathrm{m}]$ \\
\hline$m$ & mass of rotor core, $[\mathrm{kg}]$ \\
\hline$N_{\text {se }}$ & equivalent number of turns in series of stator winding, $[-]$ \\
\hline$p$ & number of pole-pairs of the motor, $[-]$ \\
\hline$\underline{p} \underline{c}_{1}$ & centre-point position of the rotor, $[\mathrm{m}]$ \\
\hline$\underline{q}_{p \pm 1}$ & transformed variables related to the cage-current components, $[\mathrm{N}]$ \\
\hline$R$ & inner radius of stator core, $[\mathrm{m}]$ \\
\hline$R_{\mathrm{r}, v}, R_{\mathrm{s}, v}$ & rotor and stator resistance of harmonic component $v,[\Omega]$ \\
\hline$R_{\omega}$ & speed ratio, [-] \\
\hline
\end{tabular}


slip of the rotor with respect to the fundamental component of the stator field, [-]

$T_{\mathrm{e}} \quad$ electromagnetic torque, $[\mathrm{N} \cdot \mathrm{m}]$

$t \quad$ time, $[\mathrm{s}]$

$\underline{\hat{u}}_{s, p} \quad$ stator voltage of fundamental component, [V]

$\underline{z}_{p \pm 1} \underline{z}_{p \pm 1} \quad$ force model parameters, [rad/s]

$\alpha \quad$ ratio between the apparent electromagnetic stiffness and the shaft stiffness, [-]

$\gamma \quad$ parameter associated with the slip and number of pole-pairs, [-]

$\delta, \delta_{\mathrm{e}} \quad$ air-gap length; equivalent air-gap length, [m]

$\delta_{i} \quad$ decay constant of eigenvalue $i,[-]$

$\zeta \quad$ factor for external viscous damping, [-]

$\mu_{0} \quad$ permeability of free space, $[\mathrm{H} / \mathrm{m}]$

$\tau_{p \pm 1} \quad$ time constants for cage-current components, [s]

$v \quad$ ordinal number of a harmonic, [-]

$\underline{\hat{\psi}}_{\mathrm{r}, p}, \hat{\hat{\psi}}_{\mathrm{s}, p}$ rotor and stator flux linkage of fundamental component, [V s $]$

$\omega \quad$ angular frequency, $[\mathrm{rad} / \mathrm{s}]$

$\omega_{\mathrm{n}} \quad$ natural bending frequency of the rotor, $[\mathrm{rad} / \mathrm{s}]$

$\omega_{\mathrm{s}} \quad$ supply frequency, $[\mathrm{rad} / \mathrm{s}]$ 

$\omega_{\mathrm{w}} \quad$ whirling frequency, $[\mathrm{rad} / \mathrm{s}]$
$\Omega_{\mathrm{m}} \quad$ rotational speed of rotor, $[\mathrm{rad} / \mathrm{s}]$
$\underline{x} \quad$ complex number
$\underline{x}^{*} \quad$ complex conjugate of $\underline{x}$
$\underline{\hat{x}} \quad$ space vector
$\tilde{x}$ dimensionless equivalent to $x$
$|\underline{x}| \quad$ magnitude of complex number $\underline{x}$
$\underline{x}^{\mathrm{r}}, \underline{x}^{\mathrm{s}} \quad$ complex number (or space-vector) in rotor or stator reference frame
$\dot{x}, \ddot{x} \quad$ first and second derivative of $x$ with respect to time
Abbreviations
FRF
Frequency Response Function
UMP
Unbalanced Magnetic Pull 


\section{Introduction}

\subsection{Background of the study}

The electromagnetic field in the air gap of an electric machine induces electromagnetic forces between the rotor and stator. An eccentric rotor position produces an unbalanced magnetic pull (UMP) appearing roughly over the shortest air gap. It is well known that one component of this eccentricity force induces additional static load, which influences bearing wear. In addition, the eccentricity force may couple the electromagnetic system with the mechanical via the flexural vibration modes of the shaft. This interaction decreases the natural frequencies and the critical speeds related to these flexural modes. Moreover, the electromechanical interaction induces additional velocitydependent forces, which may dampen the flexural rotor vibrations or produce a source for self-excited vibrations. In the worst case, the electromechanical interaction may induce rotordynamic instability leading to catastrophic failure due to stator-rotor contact during operation.

The electromechanical interaction is most significant in motors operating close to the first flexural critical speed. Because of excessive vibrations, this critical speed is usually avoided in constant speed operation, and passed as quickly as possible in transient speed-up and run-down situations. However, this is not always possible. In addition, the extended application of adjustable-speed drives has increased the requirement to operate as closely as possible to the critical speeds, and to frequently cross them. Altogether, it is evident that the rotordynamic design and vibration control of high-power motors can be greatly enhanced if the electromechanical interaction in transient operation can be described and modelled with a simple and robust model.

Figure 1 shows, as an example, the electromagnetic field of an induction motor during operation. The electromagnetic field in the cylindrical air gap around the rotor can be divided into the spatial harmonic components. The main and strongest component is the fundamental component, which is required for the generation of torque. The order of this component is the same as the number of polepairs of the machine, $p$. An eccentric rotor position together with the fundamental field component produces two additional field components in particular. The 
order of these components, $p \pm 1$, differs by one from the order of the fundamental component. The main part of the eccentricity force is produced by these additional field components together with the fundamental field. This description is complicated to some extent due to the equalising currents of the rotor cage. These harmonic currents are induced by the eccentric rotor position together with the fundamental field; it is also possible for them to induce the same field components and decrease the total eccentricity force exerted on the rotor.

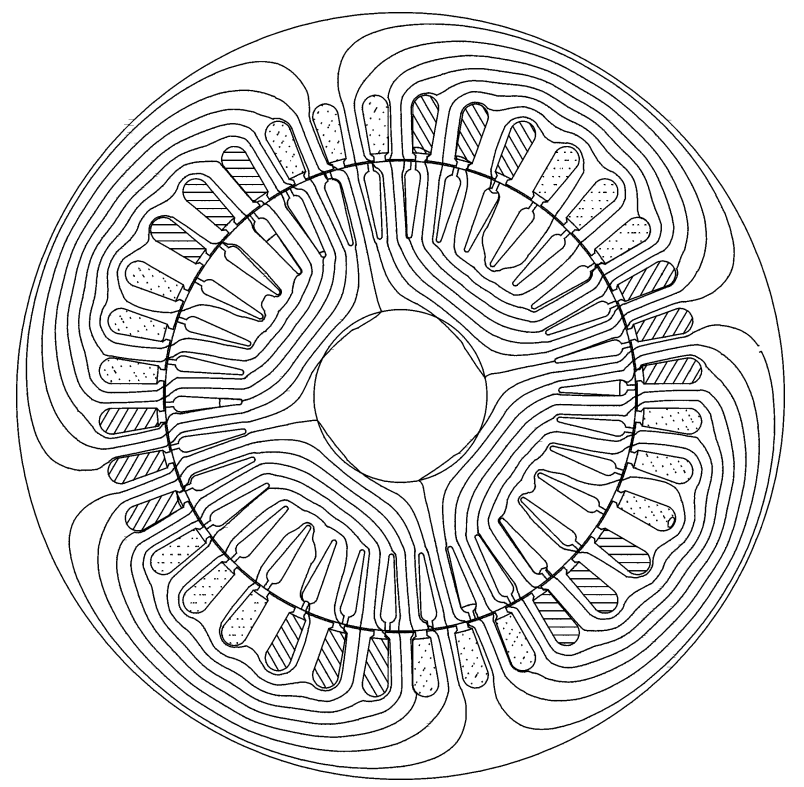

Figure 1. The magnetic field of a $15 \mathrm{~kW}$ four-pole $(p=2)$ induction motor during the rated operation. The rotor is in concentric position.

Table 1 shows the eccentricity force compared to the gravity force of the rotor for three example motors presented later in this study. As can be seen, the force ratio is largest in the smallest motor. However, in small induction motors the electromechanical interaction has only a minor effect. The reason is the relatively stiff shaft, which can be seen by comparing the rated speed and the critical speed. It appears that the electromechanical interaction is important, particularly in high-power induction motors with a flexible shaft, large bearing span and small air-gap length. The equations behind this statement will be presented and discussed later in this study. 
Table 1. The ratio between the electromagnetic force and the gravity force exerted on the rotor when the eccentricity is $10 \%$ of the air-gap length. In addition, the table shows the rated speeds and the evaluated flexural critical speeds.

\begin{tabular}{rccc}
\hline \multicolumn{1}{c}{ Motor } & Force ratio & Rated speed & Critical speed \\
\cline { 2 - 4 } & - & {$[\mathrm{rpm}]$} & {$[\mathrm{rpm}]$} \\
\hline $15 \mathrm{~kW}$ & 2.55 & 1500 & 21400 \\
$2600 \mathrm{~kW}$ & 0.29 & 3600 & 2000 \\
$4250 \mathrm{~kW}$ & 0.076 & 1800 & 2340 \\
\hline
\end{tabular}

\subsection{Aim of the work}

The main purpose of this study is to reveal the main rotordynamic consequences induced by the electromechanical interaction in cage induction motors. There is a secondary goal to achieve this by deriving a simple and representative electromechanical rotor model with physical variables and parameters.

\subsection{The scientific contribution}

The scientific contribution of this study is listed below:

1. The development of a simple electromechanical rotor model for cage induction motors.

2. The extension, generalisation, and physical explanation of the electromagnetic force model developed previously. (The term electromagnetic force model is used in this study both for the original model presented by Arkkio et al. (2000) and for the extended model presented in Publication P4. The models are equivalent in steady state operation after certain transformation of variables.)

3. The development of a method to estimate the parameters for the electromagnetic force model from the numerically simulated impulse response 
(together with Asmo Tenhunen; details of contributions are given in Section 1.4 together with the presentation of Publication P3).

4. A numerical verification of the electromechanical rotor model and the electromagnetic force model.

5. An increased understanding of the electromechanical interaction effects on the rotordynamic behaviour of cage induction motors.

Each item of this list is discussed in Section 1.4, in which the publications are presented. In addition, Table 2 summarises the relation between the scientific contribution and the publications.

Table 2. The interrelation between the scientific contribution and the publications.

\begin{tabular}{|c|c|c|c|c|c|c|}
\hline \multirow[t]{2}{*}{ Scientific contribution } & \multicolumn{6}{|c|}{ Publication } \\
\hline & $\mathrm{P} 1$ & $\mathrm{P} 2$ & $\mathrm{P} 3$ & $\mathrm{P} 4$ & P5 & P6 \\
\hline 1. Electromechanical rotor model & $\mathrm{X}$ & & & & & $\mathrm{X}$ \\
\hline 2. Electromagnetic force model & & & & $\mathrm{X}$ & & \\
\hline 3. Parameter estimation & & & $\mathrm{X}$ & & $\mathrm{X}$ & $\mathrm{X}$ \\
\hline 4. Numerical verification & & $\mathrm{X}$ & $\mathrm{X}$ & & $\mathrm{X}$ & \\
\hline 5. Effects of electromechanical interaction & $\mathrm{X}$ & & & & & $\mathrm{X}$ \\
\hline
\end{tabular}

\subsection{Publications}

The publications are listed in the order of completion.

\section{Publication P1}

In this paper, the electromagnetic force model developed previously (Arkkio et al. 2000) is combined with a simple mechanical rotor model. The derivations are carried out by applying the complex formulation. The effects of interaction are 
demonstrated using as an example a $15 \mathrm{~kW}$ four-pole motor. The possibility of rotordynamic instability is demonstrated.

The main contribution of this paper is to review the setting of the problem. This study highlights the crucial question of the physical explanation of the electromagnetic force model.

This paper was written by Holopainen. The co-authors, Tenhunen and Arkkio, contributed to the paper with several discussions and valuable comments.

\section{Publication P2}

In this paper, the simple electromechanical rotor model, presented in Publication $\mathrm{P} 1$, is verified against a more advanced numerical simulation model. The mechanical behaviour of the rotor is modelled in the same way in the both models. The simple and the more advanced models yield results that are almost the same.

The main contribution of this paper is the demonstration that the simple rotor model is well suited to investigate the effects of electromechanical interaction in the rotordynamics of electric motors.

This paper was written by Holopainen. The co-authors, Tenhunen and Arkkio, contributed to the paper with several discussions and valuable comments.

\section{Publication P3}

In this paper, a way of applying the impulse response method to estimate the parameters of the electromagnetic force model presented by Arkkio et al. (2000) is suggested. The electromagnetic system is usually non-linear due to the saturation of magnetic materials. Thus, the effective estimation of the force parameters is crucial. The derived equations show the mathematical equivalency of the impulse response method and the forced whirling method used by Arkkio et al. (2000). Further, this paper presents some additional features enhancing the capability of the impulse response method. The numerical results show that this method is very effective. In addition, the electromagnetic force model is com- 
bined with a mechanical rotor model and the feasibility of the approach for the electromechanical rotor problems is demonstrated.

The main contribution of this paper takes the form of equations that demonstrate the equivalence of the impulse response method and forced whirling method when certain prerequisite conditions are fulfilled. These equations are utilised later when a more complicated estimation problem is encountered in Publication 5.

This paper was written by Holopainen. The co-authors, Tenhunen, Lantto and Arkkio, contributed to the paper with several discussions and valuable comments. Holopainen developed his original idea of applying the impulse response method, as well as generating the first working analytical implementation of his idea. Tenhunen developed the method further and applied it, together with other authors, to several applications (Tenhunen et al. 2003a-2003e, 2004, Tenhunen 2003).

\section{Publication P4}

This paper presents a new electromagnetic force model for the eccentricity force exerted on the cage rotor due to the arbitrary rotor motion in transient operation conditions. The system equations combine the parametric force model with the space-vector model of the machine. The parameters of the model can be determined analytically from the machine characteristics or estimated numerically from the simulation of the field and circuit equations. As individual cases, the general equations were simplified for the constant flux operation, for the steadystate operation, and for the whirling motion. The form of one simplified model is equivalent to that of the electromagnetic force model presented previously (Arkkio et al. 2000).

The main contribution of this paper is the derivation of the analytical equations for the eccentricity force in arbitrary rotor motion. These equations give the physical explanation for the phenomena observed in the numerical simulations. In addition, the equations offer a framework to link together the previous analytical (e.g. Früchtenicht et al. 1982a-b), numerical (Arkkio et al. 2000), and experimental investigations (Arkkio et al. 2000). 
This paper was written by Holopainen. The co-authors, Tenhunen, Lantto and Arkkio, contributed to the paper through several discussions and valuable comments. Dr Lantto contributed by proposing and supporting the derivations of the space-vector formulation. In addition, Dr Lantto proposed the idea to simplify the general equations for the constant flux operation, which, in this connection, forms an important subcategory of operation conditions.

\section{Publication P5}

This paper presents an efficient method of estimating numerically the parameters of the new electromagnetic force model presented in Publication P4. The developed method is an extension of the impulse response method presented in Publication P3. The numerical results obtained verified the form of the new electromagnetic force model presented in Publication P4 in steady-state operation.

The main contribution of this paper is the estimation method for the parameters of the new electromagnetic force model.

This paper was written by Holopainen. The co-authors, Tenhunen, Lantto and Arkkio, contributed to the paper with several discussions and valuable comments.

\section{Publication P6}

In this paper, a new simple electromechanical rotor model is presented to assess the effects of electromechanical interaction in the rotordynamics of cage induction motors. This model combines the developed electromagnetic force model, presented in Publication P4, with a simple mechanical rotor model. The electromagnetic parameters of the example motors were estimated using the method presented in Publication P5. In this connection, two new features that enhance the feasibility of the method were applied: the averaging method and the rotating excitation pulse. To generalise the results and observations, the electromechanical rotor model was transformed into a dimensionless form. This model was used to demonstrate the main rotordynamic consequences induced by the electromechanical interaction. The results show that the electromechanical interaction may decrease the natural frequencies of the rotor, induce additional damp- 
ing or cause rotordynamic instability. These interaction effects were most significant in motors operating at, or near, the first flexural critical speed.

The main contribution of this paper is the presentation of the electromechanical rotor model. Further, the contribution includes the furthering of our understanding of the rotordynamic consequences induced by the electromechanical interaction.

This paper was written by Holopainen. The co-authors, Tenhunen and Arkkio, contributed to the paper through several discussions and valuable comments.

\subsection{Structure of the work}

The research work accomplished for this dissertation can be divided into the following major steps:

1. A detailed literature review in Chapter 2 is given to present the state-of-theart of the methods used to model electromechanical interaction in the rotordynamics of electric motors.

2. An overview of the new methods and the results obtained in this study is presented in Chapter 3.

3. A discussion of the results and the conclusions are given in Chapters 4 and 5 .

4. The publications are reprinted in Appendices I-VI. 


\section{Overview of the electromechanical interaction in rotordynamics}

This literature survey focuses on the electromechanical interaction in the rotordynamics of electric machines. There are several subjects closely related to this topic. One of these is the UMP due to the eccentric rotor motion. There are two fresh literature reviews on this subject written by Tenhunen (2003) and Dorrell (1993). The UMP represents the total force exerted on the rotor. The spatial distribution of the electromagnetically induced forces are discussed and reviewed by Tímár (1989) and Yang (1981). The effects of electromechanical interaction on torsional vibrations have been historically more important than on lateral. A short state-of-the-art review and literature survey of torsional vibrations is given by Belmans (1994). In the current literature study, all the above-mentioned overlapping fields of research are left outside its scope, as the focus is on the electromechanical interaction in lateral rotor vibrations of electric machines.

\subsection{Critical speed of electric machines}

Föppl (1895) introduced the most simple rotor model, which is still in active use. This model usually bears the name of Jeffcott (1919), probably because his presentation of the rotordynamics with this same model was so clear. The equations of motion for this simple rotor model with unbalance excitation can be written using the complex formulation of (Childs 1993)

$$
m \underline{\ddot{p}}_{\mathrm{c}}+d \underline{\dot{p}}_{\mathrm{c}}+k \underline{p}_{\mathrm{c}}=m \underline{a} \Omega_{\mathrm{m}}{ }^{2} \mathrm{e}^{\mathrm{j} \Omega_{\mathrm{m}} t}
$$

where $\underline{p}_{\mathrm{c}}$ is the centre-point position of the rotor, the bar under a symbol denotes the complex quantity, $m$ is the mass of the rotor, $d$ the external viscous damping, $k$ the shaft stiffness, $\underline{a}$ describes the unbalance vector, $\Omega_{\mathrm{m}}$ is the rotational speed of the rotor, the dot above a symbol denotes the first derivative with respect to time, and the double dot the second. The critical speed of this rotor model, corresponding to the resonance frequency of the system, can be written 


$$
\Omega_{\mathrm{m}, \mathrm{rr}}=\sqrt{\frac{k}{m}}
$$

if the effect of damping is ignored.

Rosenberg $(1917,1918)$ was the first researcher, who reported, first in German, then in English, the effects of UMP on the rotordynamic behaviour of electric machines. He proposed a formula to estimate the critical speed of electric machines

$$
n_{\mathrm{cr}}=\sqrt{1-q} \cdot \frac{300}{\sqrt{u}}
$$

where $n_{\text {cr }}$ is the critical speed in revolutions per minute, $u$ the deflection (given in $\mathrm{cm}$ ) of the horizontally placed shaft under the static influence of the rotor weight, and $q$ the "ratio between the combined deflection of all the machine parts, caused by unbalanced pull, to the displacement, causing the unbalanced pull". The last part of the equation, $300 / \sqrt{u}$, is a well-known practical formula to determine the critical speed. For the focal parameter $q$, Rosenberg gives simplified formulas depending on the type of machine and the maximum allowable value.

\subsection{Electromagnetic stiffness and damping}

Freise (1961), and Freise \& Jordan (1962) presented the analytical equations for the UMP induced by the eccentric rotor. Further, they introduced the coefficients for the force reduction induced by the equalising currents of the rotor cage. Finally, they presented a simple formula to determine the first critical speed starting from the negative spring coefficient induced by the electromagnetic field. They wrote the equation of critical speed in the form

$$
\Omega_{\mathrm{m}, \mathrm{rr}}=\sqrt{\frac{k-k_{\mathrm{e}}}{m}}
$$


where $k_{\mathrm{e}}$ is the negative spring coefficient. Freise \& Jordan (1962) derived the approximate formula for this coefficient

$$
k_{\mathrm{e}}=\frac{\pi d_{\mathrm{s}} l_{\mathrm{e}}}{4 \mu_{0} \delta} \cdot u v o \cdot\left(\frac{w_{p-1}+w_{p+1}}{2}\right) \cdot B_{p}^{2}
$$

where $d_{\mathrm{s}}$ is the inner diameter of the stator core, $l_{\mathrm{e}}$ the equivalent core length, $\mu_{0}$ the permeability of air, $\delta$ the air-gap length, $B_{p}$ the amplitude of the magnetic field density for the fundamental component, $w_{p \pm 1}$ the reduction factors due to the harmonic currents of the rotor cage, $u$ and $v$ the coefficients related to the eccentricity, and $o$ the reduction factor related to the operation condition.

Haase (1973) and Haase et al. (1973) introduced the damping coefficient induced by the electromagnetic fields. They observed during the updating of an induction machine that the stator slotting harmonics were related to harmful rotor vibrations. This led to the study of higher harmonics and further research into the introduction of the electromagnetically induced damping coefficient. They presented the electromagnetic force components in the form

$$
\underline{F}_{\mathrm{e}, \nu}=-\left(d_{\mathrm{e}, \nu} \underline{\dot{p}}_{\mathrm{c}, \nu}+k_{\mathrm{e}, \nu} \underline{p}_{\mathrm{c}, \nu}\right)
$$

where $v$ is the ordinal number of the component. The additional stiffness and damping coefficients were defined as

$$
\begin{aligned}
& k_{\mathrm{e}, v}=-\frac{\pi R l B_{p}^{2}}{4 \mu_{0} \delta_{\mathrm{e}}} \frac{p}{v} \frac{\xi_{v}^{\prime}}{\xi_{p}^{\prime}}\left(\frac{p}{v} \frac{\xi_{v}^{\prime}}{\xi_{p}^{\prime}}+\frac{\Lambda_{\mathrm{N}}^{\prime}}{2}\right)\left[\alpha_{v}\left(\alpha_{v+1}+\alpha_{v-1}\right)+\beta_{v}\left(\beta_{v+1}+\beta_{v-1}\right)\right] \\
& d_{\mathrm{e}, v}=\frac{\pi R l B_{p}^{2} \omega_{\mathrm{e}, v}}{4 \mu_{0} \delta_{\mathrm{e}}} \frac{p}{v} \frac{\xi_{v}^{\prime}}{\xi_{p}^{\prime}}\left(\frac{p}{v} \frac{\xi_{v}^{\prime}}{\xi_{p}^{\prime}}+\frac{\Lambda_{\mathrm{N}}^{\prime}}{2}\right)\left[\alpha_{v}\left(\beta_{v+1}-\beta_{v-1}\right)-\beta_{v}\left(\alpha_{v+1}-\alpha_{v-1}\right)\right]
\end{aligned}
$$

where $R$ is the inner radius of the stator core, $\delta_{\mathrm{e}}$ the equivalent air-gap length, $\xi_{v}^{\prime}$ the stator winding factor associated with the component $v, \Lambda_{\mathrm{N}}^{\prime}$ the amplitude of relative permeability variation associated with the stator slotting, $\alpha_{v}$ and $\beta_{v}$ the real and negative imaginary parts of the damping factors due to the 
equalising currents, and $\omega_{\mathrm{e}, \nu}=\sqrt{\left(k-k_{\mathrm{e}, \nu}\right) / m}$ the undamped flexural eigenfrequency of the rotor associated with the component $v$.

Brosch et al. (1974) reviewed the electromagnetic reasons behind the vibrations of electric machines. They divided these into five categories: the effect of UMP on the flexural frequencies, the generation of electromagnetic total force exerted on the rotor, the effects of negative electromagnetic damping, the effects of homopolar flux, and the instability following from the periodic alteration of the effective shaft stiffness.

\subsection{Rotordynamic instability}

Krondl (1956) was the first researcher who observed the self-excited vibrations in induction motors. He applied analytical methods and concluded that the reason for the observed vibrations was the parallel branches of the stator windings.

Kellenberger (1966) investigated the forced motion of a rotating, two-pole turboalternator due to the mass unbalance and the UMP. He found out that the tangential component of the magnetic pull, which was usually neglected, could be the cause of large or even unrestricted growth in the deflection, despite the presence of mechanical damping. He proposed a system of linear differential equations with harmonic coefficients as a possible solution to this problem of mechanical instability.

Geysen et al. (1979) investigated the self-excited vibrations, both torsional and flexural, in alternating-current machines. They introduced the internal mechanical damping into the investigations. Internal damping is known to induce rotordynamic instability during supercritical operation. They presented two different stability charts having the speed ratio on one axis and a function of damping coefficients on the other axis. They concluded that the internal damping coefficient was the most important factor; the value of this coefficient can lead to different results depending on whether the operation is sub- or supercritical.

Früchtenicht et al. (1980) studied the electromagnetic effects on the rotor vibrations of alternating current motors. They derived a model, which couples 
together the torsional and transversal vibrations via the reluctance torque and the mass unbalance. In addition, they investigated theoretically the electromagnetic instability, and presented the contour charts for the stiffness coefficient, the damping coefficient, and the natural flexural frequency as functions of fundamental field amplitude and rotational speed.

Früchtenicht et al. (1982a) derived an analytic model for the UMP when the rotor is in a circular whirling motion with an arbitrary whirling frequency. They applied the assumption that the currents and fluxes vary sinusoidally in time. Using this model they determined the additional stiffness and damping coefficients induced by the electromagnetic fields. The analytical formula for the stiffness coefficient is

$$
\begin{array}{r}
k_{\mathrm{e}}=-\frac{\pi l B_{p}^{2}}{4 \mu_{0}} \cdot\left[\frac{2 R}{\delta_{\mathrm{e}}}-\frac{s_{p+1}^{2}}{s_{p+1}^{2}+\beta_{p+1}^{2}} \cdot \frac{\xi_{p+1}^{2} \cdot \xi_{\text {Schr } . p+1}^{2}}{1+\sigma_{g R p+1}} \cdot\left(\frac{R}{\delta_{\mathrm{e}}}-p-1\right)+\right. \\
\left.-\frac{s_{p-1}^{2}}{s_{p-1}^{2}+\beta_{p-1}^{2}} \cdot \frac{\xi_{p-1}^{2} \cdot \xi_{\text {Schr } p-1}^{2}}{1+\sigma_{g R p-1}} \cdot\left(\frac{R}{\delta_{\mathrm{e}}}+p-1\right)\right]
\end{array}
$$

and for the damping coefficient

$$
\begin{aligned}
d_{\mathrm{e}}=\frac{\pi l B_{p}^{2}}{4 \mu_{0} \Omega_{\mathrm{m}}} & \cdot\left[\frac{s_{p+1} \cdot \beta_{p+1}}{s_{p+1}^{2}+\beta_{p+1}^{2}} \cdot \frac{\xi_{p+1}^{2} \cdot \xi_{\text {Schr } p+1}^{2}}{1+\sigma_{g R p+1}} \cdot\left(\frac{R}{\delta_{\mathrm{e}}}-p-1\right)+\right. \\
& \left.-\frac{s_{p-1} \cdot \beta_{p-1}}{s_{p-1}^{2}+\beta_{p-1}^{2}} \cdot \frac{\xi_{p-1}^{2} \cdot \xi_{\text {Schr } . p-1}^{2}}{1+\sigma_{g R p-1}} \cdot\left(\frac{R}{\delta_{\mathrm{e}}}+p-1\right)\right]
\end{aligned}
$$

where $s_{p \pm 1}$ are the slips of the rotor with respect to the eccentricity harmonic fields, $\beta_{p \pm 1}$ the resistance-reactance ratios of the rotor mesh, $\xi_{p \pm 1}$ the winding factors of the eccentricity harmonics, $\xi_{\text {schr. } p \pm 1}$ the skew factors of the eccentricity harmonics, and $\sigma_{g R p \pm 1}$ the geometrical leakage coefficients of the eccentricity harmonics. Using these coefficients, together with the Jeffcott rotor model including the contributions of the external and internal damping, Früchtenicht et al. (1982b) developed an electromechanical model to study the effects of electromechanical interaction on the rotordynamic stability. They presented two stability charts resembling closely those presented by Geysen et al. (1979). In addition, they constructed a test rig using the electrical parts of a four-pole 11 
$\mathrm{kW}$ standard motor equipped with an especially designed flexible shaft. Finally, they compared the numerical and experimental results and observed a good correlation.

The approach of Skubov \& Shumakovich (1999) enabled an arbitrary motion of the rotor. They applied the averaging method together with the Lagrange formulation for the analytical derivation of the equations. The variables of this system were the two harmonic components of the rotor flux linkages, and the rotor position and rotation angle. They discovered that the tangential component of the electromagnetic total force might be the reason for the instability.

Yang et al. (1999) and Yang et al. (2004) presented a general analytical method to evaluate rotordynamic stability of induction motors. In this approach, the electromagnetic force is proportional to the eccentricity. In addition, the electromagnetic force includes a time-dependent component at two times the electric line frequency. The approach is based on the time-transfer-matrix method and the Floquet theory.

\subsection{Two-pole motors and homopolar flux}

Kovács (1977) investigated the vibrations of two-pole induction motors induced by homopolar flux. He included in his model the radial component of the force and defined the electromagnetic spring constant.

Belmans (1984), Belmans et al. (1984a and 1984b) and Belmans et al. (1987) investigated analytically and experimentally the radial vibrations and stability of two-pole induction motors. They concluded that the homopolar flux generated by the eccentric rotor position clearly influences the UMP in two-pole induction motors, not only by altering the value of the constant component of the pull, but also by generating a pull component with a frequency twice that of the slip. In addition, they concluded that a potential reason for the rotordynamic instability results from the electromagnetic damping coefficient, which may be negative. Based partly on the above-mentioned investigations, Belmans (1994) presented a review discussing the mechanical and magnetical aspects of the radial vibrations of electrical machines. 


\subsection{Refinement of analytical methods}

Chaban et al. (1990) derived electromechanical equations to analyse torsional and transversal rotor vibrations of induction motors. The differential equations of the electromagnetic system were highly idealised. In addition to the mechanical variables, the equations included the variables for the flux linkages of the rotor and stator related to the fundamental component. Using this model they calculated the coupled behaviour of an unloaded induction motor in start-up condition.

Dorrell (1993, 1996), Dorrell \& Smith (1994), Smith \& Dorrell (1996) developed an analytical method to determine the UMP induced by an eccentric rotor. The model uses the conformal transformation technique combined with the winding impedance approach. They applied the method to investigate the effect of rotor skew and series or parallel winding connections. Dorrell \& Smith (1996) validated the model with extensive measurements.

Toliyat et al. (1996) proposed a new method that enables the simulation of airgap eccentricity in induction machines. The approach is based on the coupled magnetic circuit approach. Joksimovic et al. (2000) presented a method for the dynamic simulation of dynamic eccentricity in the cage induction motor. The method is based on a winding function approach, which allows for all the harmonics of magnetomotive force to be taken into account.

Guo et al. (2002) investigated the UMP and its effects on vibration in a threephase generator with an eccentric rotor. They derived the analytical equations for the UMP starting from the expression of air-gap permeance. The equations are suitable for the machines of any number of pole-pairs and they include the effect of large relative eccentricity.

\subsection{Computational methods}

Benaragama et al. (1982) was the first to apply FEM to investigate the UMP. His research subject was a synchronous turbo-generator. Over a decade later, Salon et al. (1992), DeBortoli et al. (1993), Arkkio \& Lindgren (1994), Arkkio (1996) 
extended the application area to induction motors, equalising currents and parallel circuits of the stator windings.

Stoll (1997) developed a simple computational model to predict the UMP caused by static eccentricity. The effects of rotor saturation and eddy currents are taken into account using a set of rotor surface impedances.

Arkkio et al. (2000) studied the UMP exerted on the rotor of a $15 \mathrm{~kW}$ cage induction motor. They determined numerically the UMP in circular whirling motion as a function of whirling frequency. They validated the numerical results with the experimental measurements using a rigid rotor and two magnetic bearings to generate the controlled whirling motion. They found out that the relation between the UMP and the whirling motion could be presented with a low-order model

$$
\underline{F}_{\mathrm{e}}\left(\mathrm{j} \omega_{\mathrm{w}}\right)=\underline{G}\left(\mathrm{j} \omega_{\mathrm{w}}\right) \cdot \underline{p}_{\mathrm{c}}\left(\mathrm{j} \omega_{\mathrm{w}}\right)
$$

where $\underline{F}_{\mathrm{e}}$ is the total electromagnetic force exerted on the rotor, the bar under a symbol denotes the complex quantity, $\omega_{\mathrm{w}}$ is the whirling frequency, $p_{\mathrm{c}}$ the centre-point position of the rotor, and $\underline{G}$ the frequency response function (FRF), which can be parameterised as

$$
\underline{G}\left(\mathrm{j} \omega_{\mathrm{w}}\right)=k_{0}+\frac{\underline{k}_{p-1}}{\mathrm{j} \omega_{\mathrm{w}}-\underline{z}_{p-1}}+\frac{\underline{k}_{p+1}}{\mathrm{j} \omega_{\mathrm{w}}-\underline{z}_{p+1}}
$$

where $k_{0}, \underline{z}_{p \pm 1}$, and $\underline{k}_{p \pm 1}$ are the parameters of the system. Actually, the form of this FRF is the same as presented by Früchtenicht et al. (1982a). Arkkio et al. (2000) continued by transforming Equation (11) into the form of differential equations

$$
\begin{aligned}
& \underline{\dot{q}}_{p-1}=\underline{z}_{p-1} \underline{q}_{p-1}+\underline{k}_{p-1} \underline{p}_{\mathrm{c}}(t) \\
& \underline{\dot{q}}_{p+1}=\underline{z}_{p+1} \underline{q}_{p+1}+\underline{k}_{p+1} \underline{p}_{\mathrm{c}}(t) \\
& \underline{F}_{\mathrm{e}}(t)=k_{0} \underline{p}_{\mathrm{c}}(t)+\underline{q}_{p-1}+\underline{q}_{p+1}
\end{aligned}
$$


where $t$ is the time, and $\underline{q}_{p-1}$ and $\underline{q}_{p+1}$ are the new variables related to the harmonic components $p \pm 1$ of the rotor-cage currents.

Ha et al. (1999) presented an approach to analyse the rotor vibrations and stresses of interior-permanent-magnet type synchronous motors. The studied synchronous motor was equipped with interior permanent magnets, and the approach was based on the transfer matrix method. Further, Ha et al. (2000) and Ha \& Hong (2001) proposed an approach to calculate the orbital response of the rotor for switched reluctance motors. In this approach, the rotor shaft is modelled by the finite element method with beam elements. The electromagnetic force due to the rotor eccentricity is determined using an analytical formula based on the Maxwell stress tensor (Ha et al. 2000), or by the finite element method

Kim et al. (2000) presented a method to analyse transient responses of a permanent magnet motor including the effects of electromechanical interaction. In this case, the rotor does not include a cage or corresponding structural arrangement. The rotor-motor system of a compressor is modelled using the finite-element-transfer-matrix method and the electromagnetic field in the air gap with analytical equations. The results show that the electromechanical coupling increases the system vibration by reducing the system stiffness in the radial direction. Later, Kim et al. $(2001 a, 2001 b)$ applied this approach to the comparison of vibration characteristics of interior and surface mounted permanent magnet motors.

\subsection{Experimental studies on cage-rotor vibrations}

Iwata \& Sato (1997) and Iwata et al. (2001) studied experimentally rotor vibrations of an experimental induction motor. They constructed an open set-up with a vertical rotor suspended from the upper end. They measured the response of various harmonic components of electromagnetic forces and studied the effects of supply frequency and rotor eccentricity.

Amati \& Brusa (2001) carried out condition monitoring experiments using a spindle prototype on active magnetic bearings fed by an induction motor. They 
discovered that the UMP of an induction motor may affect strongly the dynamic behaviour of the system.

\subsection{Bearingless induction motors}

A bearingless motor is an integrated device that possesses magnetic bearing capability in addition to having the torque-producing function. Various types of bearingless motors have been proposed. The main types of bearingless motors are the switched reluctance, asynchronous and permanent magnet motors (Amrhein et al. 2003). Here, our focus is on bearingless induction motors. The principle of magnetic force production in bearingless motors is the creation of an unbalanced flux distribution in the air gap by supplying additional levitation currents to the stator windings. This magnetic suspension force is usually modelled with analytical equations and used in the magnetic suspension loop. Chiba, Power \& Rahman $(1991 a, 1991 b)$ were probably the first to present the principle and working concept for a bearingless induction motor. The magnetic force exerted on the rotor is a function of additional levitation currents and rotor eccentricity. This suspension force has been investigated by, for example, Chiba et al. (1994), Kiryu et al. (2001) and He \& Nian (2003). They applied analytical and experimental methods. Cai \& Henneberger (2001) and Baoguo \& Fengxiang (2001) used FEM to calculate the radial force due to the eccentricity.

\subsection{Practical applications}

Wright et al. (1982) presented a practical method of taking into account the influence of pole number on unbalance magnetic pull. In addition, they proposed an explanation for the anomalous behaviour of the two-pole machines, and demonstrated the relatively minor influence of the UMP on the critical speed.

Merrill (1994) reviews the dynamics of alternating current motors. In his own words, the paper is a qualitative review as interpreted by an electrical motor design engineer. It is possible to interpret the procedures described in the paper as customary practice in the electric-machine industry. For the negative spring constant he gives a formula corresponding to 


$$
k_{\mathrm{e}}=\frac{\pi d_{\mathrm{s}} l B_{p}^{2}}{4 \mu_{0} \delta}
$$

Regarding the design criteria, Merrill (1994) mentions that good practice suggests the ratio $k / k_{\mathrm{e}} \geq 3.0$ for pedestal type machines, and $k / k_{\mathrm{e}} \geq 2.5$ for bracket type machines. In a rather similar review paper, Owen (1991) mentions that the role of UMP is sometimes exaggerated in rotor-dynamics analysis. He continues that it is true that the effect of the magnetic force is equivalent to a negative spring constant for the shaft, but that it is usually only a second-order effect.

Baumgardner (1994), Finley et al. (2000) and Mansoor (2002) present practical guidelines for the vibration control of induction motors at low frequency range. The papers show clearly that a thorough knowledge of electromagnetic forces and rotordynamics is required to successfully control the vibrations of large induction motors.

The design, manufacturing and testing of large-power, high-speed motors and generators must be carried out much more carefully than usual. This is true particularly with respect to rotordynamics and vibration control. These machines operate usually in a super-critical frequency range. Bressani et al. (1993) presented their experience in the design, manufacturing and testing of highspeed induction motors for variable-speed drives without analytical details. The rated power of the studied motors was up to 6.6 MW. Hamer et al. (1995) describe experiences with, and design refinements for, large two-pole induction motors rated up to $4.5 \mathrm{MW}$. These motors were designed to operate below the first critical speed. The design, fabrication and testing of a still larger motor (10.6 MW) for adjustable speed drive was presented by McSharry et al. (1998). Bettig \& Han (1999) presented a detailed rotordynamic model for a $34 \mathrm{MW}$ vertical axis hydraulic turbine-generator. The electromagnetic force was modelled using Equation (13) multiplied by Carter's coefficient (Heller \& Hamata 1977). McClurg et al. (2003) describe a replacement of an existing motor by a 7.5 MW, four-pole induction motor. In this application, the specified requirements for vibration, noise and electrical performance were high. 


\section{New methods of analysis}

\subsection{Impulse method to parameter estimation}

The immediate starting point for this study was the simple linear model for the UMP presented by Arkkio et al. (2000), and shown in Equation (12). The parameters of this model can be estimated from the FRF shown in Equation (11). To determine the value of the FRF at one whirling frequency, Arkkio et al. (2000) carried out one numerical simulation forcing the centre point of the rotor to move along a circular path at constant speed. This meant that several computer runs had to be calculated to determine the FRF. Thus, a lot of numerical resources were required to estimate the model parameters using this method, which will be called here the forced whirling method.

An effective approach was proposed by Tenhunen et al. (2003c) and in Publication P3 to generate the FRF directly from the impulse response. In this method, the rotor is displaced from its concentric position for a short period of time. In the analysis, the discrete Fourier transformation is applied for the time histories of the electromagnetic force and the displacement signals. Finally, the FRF is obtained by dividing the transformed electromagnetic force by the transformed displacement.

The developed methods were applied to four induction motors. Table 3 shows the main parameters of these motors. Figure 2 shows a typical simulated force response of the $15 \mathrm{~kW}$ motor excited by a rotating excitation pulse between $0.08-0.12 \mathrm{~s}$. The decaying part of the response is connected to the cage-current components. As can be seen in Figure 2, the electromagnetic force deviates clearly from zero after the pulse, though the displacement and velocity of the rotor are identically zero. This leads to the conclusion that the previous models expressing the electromagnetic force with additional stiffness and damping coefficients, i.e., in the form

$$
\underline{F}_{\mathrm{e}}=d_{\mathrm{e}} \underline{\dot{p}}_{\mathrm{c}}+k_{\mathrm{e}} \underline{p}_{\mathrm{c}}
$$

cannot describe the general behaviour of the eccentricity force. 
Table 3. Main parameters of the example motors. The mechanical characteristics of the $18 \mathrm{~kW}$ motor are modified from the standard values for experimental research purposes.

\begin{tabular}{lrrrrl}
\hline Parameter & Motor & & & \multicolumn{2}{c}{ Unit } \\
\cline { 2 - 5 } & $15 \mathrm{~kW}$ & $18 \mathrm{~kW}$ & $2.6 \mathrm{MW}$ & $4.2 \mathrm{MW}$ & \\
\hline Number of poles & 4 & 6 & 2 & 4 & \\
Rated voltage & 380 & 400 & 4000 & 13200 & $\mathrm{~V}$ \\
Rated current & 28 & 30 & 417 & 217 & $\mathrm{~A}$ \\
Rated frequency & 50 & 50 & 60 & 60 & $\mathrm{~Hz}$ \\
Rotor effective mass & 30 & 68 & 1100 & 2500 & $\mathrm{Kg}$ \\
Rotor effective stiffness & 150 & 2.8 & 48 & 150 & $\mathrm{MN} / \mathrm{m}$ \\
Natural flexural freq. & 356 & 30 & 33 & 39 & $\mathrm{~Hz}$ \\
\hline
\end{tabular}

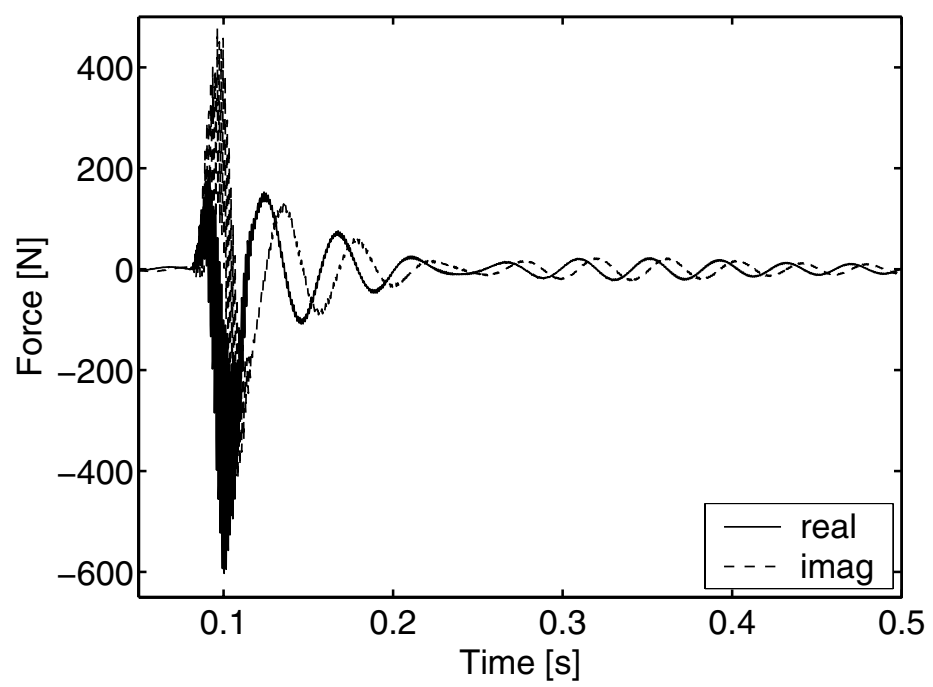

Figure 2. Transient force response of the $15 \mathrm{~kW}$ motor at rated load and voltage due to an eccentric rotor motion between 0.08-0.12 s. The electromagnetic force is divided into the real and imaginary components.

Figure 3 presents the FRF of this same motor determined by the impulse response method together with the discrete values determined by the forced whirling method. The radial component is defined in the direction of the shortest 
air gap and the tangential component perpendicular to the radial one. As can be seen, both methods yield almost equivalent results.

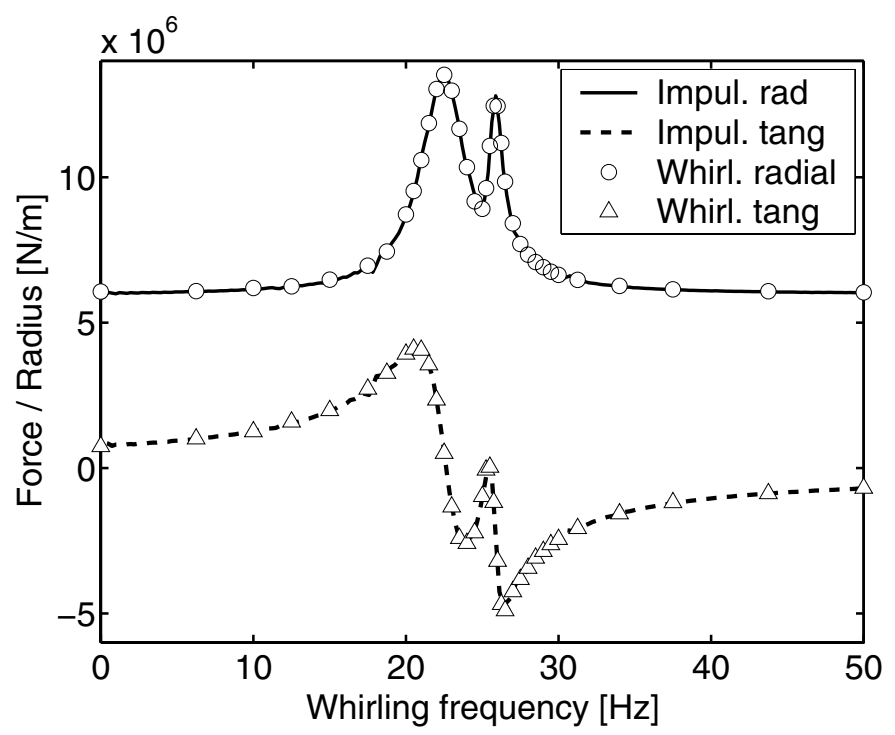

Figure 3. The radial and tangential components of the FRF in the stator reference frame calculated by the impulse method. For comparison, the discrete values obtained by the forced whirling method with radius $50 \mu \mathrm{m}$ are also given (Arkkio et al. 2000).

The application of the impulse method, although based on the well-known spectral analysis techniques, is not a self-evident approach for the estimation of the force parameters. The difficulties result mainly from the non-linearity of the system, the rotating reference frames, and the complex formulation. It can be shown (Publication P3) that the impulse method and the previously-used forced whirling method are equivalent when certain preconditions are fulfilled. Moreover, some additional techniques, such as the zero padding and exponential windowing, can be effectively used to shorten the required simulation time (Publication P3).

During the past few years, the impulse method has been widely applied to different studies related to the eccentricity forces. Tenhunen, Holopainen, and Arkkio applied the method to study the spatial linearity of the UMP (2003d), and to investigate the effects of saturation (2004) and the equalising currents (2003e) 
on the UMP. Moreover, Tenhunen et al. (2003a, 2003b) extended the impulse method to study the electromagnetic forces exerted on the cage rotor in conical whirling motion. Especially important was the study of spatial linearity (Tenhunen et al. 2003d). This special property of a strongly non-linear system allows the simple approach to model electromechanical interaction applied in this study.

As regards to this dissertation, the presented impulse method was used as the starting point to develop a parameter estimation method for the new electromagnetic force model discussed in Sections 3.3 and 3.4.

\subsection{Electromagnetic force model}

Früchtenicht et al. (1982a) derived the analytical equations for the UMP when the rotor is in circular whirling motion with arbitrary whirling frequency. They applied the assumption that the currents and fluxes vary sinusoidally in time. For arbitrary rotor motion this assumption is not valid. Arkkio et al. (2000) identified a parametric FRF for the total electromagnetic force presented in Equation (11). To achieve this goal, they applied numerical and experimental methods together with circular whirling motion. The form of this parametric FRF corresponds to the analytical equations of Früchtenicht et al. (1982a). Further, Arkkio et al. (2000) transformed the parametric FRF into the form of differential equations including two new variables, $\underline{q}_{p-1}$ and $\underline{q}_{p+1}$, presented in Equation (12). These new variables were not clearly related to the analytical equations derived previously or to the machine characteristics, and thus, the physical background of the parametric force model was still partly hidden.

Publication P4 presents a new model for the eccentricity force exerted on the cage rotor due to the arbitrary rotor motion. This parametric model is simple and can be applied in transient operation conditions. The system of equations combines the space-vector model of the machine (Kovács 1984, Müller 1985) to the new parametric force model. The space-vector model of an induction motor can be presented by two voltage, and two flux, equations 


$$
\begin{aligned}
& R_{\mathrm{s}, p} \underline{\hat{i}}_{\mathrm{s}, p}^{\mathrm{r}}+\frac{\mathrm{d} \hat{\hat{\psi}}_{\mathrm{s}, p}^{\mathrm{r}}}{\mathrm{d} t}+\mathrm{j} p \Omega_{\mathrm{m}} \underline{\hat{\psi}}_{\mathrm{s}, p}^{\mathrm{r}}=\underline{\hat{u}}_{\mathrm{s}, p}^{\mathrm{r}} \\
& R_{\mathrm{r}, p} \hat{\hat{i}}_{\mathrm{re}, p}^{\mathrm{r}}+\frac{\mathrm{d} \hat{\psi}_{\mathrm{r}, p}^{\mathrm{r}}}{\mathrm{d} t}=0 \\
& \underline{\hat{\psi}}_{\mathrm{s}, p}^{\mathrm{r}}=L_{\mathrm{s} \sigma, p} \hat{\hat{i}}_{\mathrm{s}, p}^{\mathrm{r}}+L_{\mathrm{m}, p}\left(\underline{\hat{i}}_{\mathrm{s}, p}^{\mathrm{r}}+\underline{\hat{i}}_{\mathrm{re}, p}^{\mathrm{r}}\right) \\
& \hat{\psi}_{\mathrm{r}, p}^{\mathrm{r}}=L_{\mathrm{r \sigma}, p} \underline{\hat{i}}_{\mathrm{re}, p}^{\mathrm{r}}+L_{\mathrm{m}, p}\left(\hat{i}_{\mathrm{s}, p}^{\mathrm{r}}+\underline{\hat{i}}_{\mathrm{re}, p}^{\mathrm{r}}\right)
\end{aligned}
$$

where the subscripts $\mathrm{s}, \mathrm{r}$, and re refer to the stator, rotor, and equivalent rotor values, respectively, the subscript after a comma refers to the ordinal number of harmonic component, superscript $r$ to the rotor reference frame, a bar under a symbol denotes a complex quantity, $\underline{\hat{u}}, \underline{\hat{\psi}}$, and $\underline{\hat{i}}$ are the space vectors of the supply voltage, flux linkage, and current, respectively, $R$ is the resistance, $L_{\mathrm{m}}$ the magnetising inductance of the three-phase winding, $L_{\mathrm{s} \sigma}$ and $L_{\mathrm{r} \sigma}$ the leakage inductance's of the stator and rotor, respectively, and $\Omega_{\mathrm{m}}$ the mechanical angular frequency of the rotor. The input values of Equations (15) are the space-vector of stator voltage and the angular velocity of the rotor. The required equations for the eccentricity harmonics due to the rotor motion are

$$
\begin{aligned}
& L_{\mathrm{r}, p-1} \frac{\mathrm{d} \underline{\hat{i}}_{\mathrm{r}, p-1}^{\mathrm{r}}}{\mathrm{d} t}+R_{\mathrm{r}, p-1} \hat{i}_{\mathrm{r}, p-1}^{\mathrm{r}}+\frac{L k_{p-1}}{2 \mu_{0}} \cdot \frac{\mathrm{d}}{\mathrm{d} t}\left(\hat{B}_{\delta, p}^{\mathrm{r}} \underline{p}_{\mathrm{c}}^{\mathrm{r}}\right)=0 \\
& L_{\mathrm{r}, p+1} \frac{\mathrm{d} \hat{i}_{\mathrm{r}, p+1}^{\mathrm{r}}}{\mathrm{d} t}+R_{\mathrm{r}, p+1} \hat{\hat{i}}_{\mathrm{r}, p+1}^{\mathrm{r}}+\frac{L k_{p+1}}{2 \mu_{0}} \cdot \frac{\mathrm{d}}{\mathrm{d} t}\left(\hat{B}_{\delta, p}^{\mathrm{r}} \underline{p}_{\mathrm{c}}^{\mathrm{r}}\right)=0
\end{aligned}
$$

where $L_{\mathrm{r}, p \pm 1}$ and $R_{\mathrm{r}, p \pm 1}$ are the rotor-cage inductances and resistances of harmonic components $p \pm 1$, respectively, $k_{p \pm 1}$ are the coupling factors due to the leakage flux and saturation, $L$ is the self-inductance of one rotor-cage mesh, $\underline{p}_{\mathrm{c}}$ the centre-point position of the rotor, the asterix $\left(^{*}\right)$ denotes the complex conjugate, and $\underline{\hat{B}}_{\delta, p}^{\mathrm{r}}$ is the space-vector of the magnetic flux density in the air gap. 
The only coupling between Equations (15) and (16) is the relation between the fundamental component of the magnetic flux density and the rotor and stator currents

$$
\underline{\hat{B}}_{\delta, p}^{\mathrm{r}}=\frac{\mu_{0}}{\delta_{\mathrm{e}}} \frac{3}{2} \frac{N_{\mathrm{se}}}{2 p} \cdot\left(\underline{\hat{i}}_{\mathrm{s}, p}^{\mathrm{r}}+\underline{\hat{i}}_{\mathrm{re}, p}^{\mathrm{r}}\right)
$$

where $\delta_{\mathrm{e}}$ is the equivalent air-gap length, and $N_{\mathrm{se}}$ the equivalent number of turns in series of the stator winding. Further, the transversal force and, for the sake of completeness, the equation for instantaneous electromagnetic torque (Kovács 1984) can be written

$$
\begin{aligned}
& \underline{F}_{\mathrm{e}}^{\mathrm{r}}=\frac{\pi d_{\mathrm{r}} l_{\mathrm{e}}}{4 \mu_{0} \delta} \cdot\left(\left|\underline{\hat{B}}_{\delta, p}^{\mathrm{r}}\right|^{2} \cdot \underline{p}_{\mathrm{c}}^{\mathrm{r}}+\mu_{0} k_{p-1} \underline{\hat{B}}_{\delta, p}^{\mathrm{r}} \hat{\underline{\hat{i}}}_{\mathrm{r}, p-1}^{\mathrm{r}}{ }^{*}+\mu_{0} k_{p+1} \underline{\hat{B}}_{\delta, p}^{\mathrm{r}}{ }^{*} \hat{\underline{\hat{i}}}_{\mathrm{r}, p+1}^{\mathrm{r}}\right) \\
& T_{\mathrm{e}}=\frac{3}{2} p \operatorname{Im}\left\{\underline{\hat{\psi}}_{\mathrm{s}, p}^{\mathrm{r}}{ }^{*} \hat{\underline{\hat{i}}}_{\mathrm{s}, p}^{\mathrm{r}}\right\}
\end{aligned}
$$

where $d_{\mathrm{r}}$ is the outer diameter of the rotor, $l_{\mathrm{e}}$ the equivalent core length, and $|\cdot|$ denotes the length of a space vector.

Equations (15)-(18) describe the electromagnetic force and torque in general form. An important, and often occurring, particular case is the one where the amplitude of the magnetic flux density is constant or changing so slowly that the term related to the change can be disregarded. In this special case, the equations for the eccentricity force can be written in the stator reference frame as

$$
\begin{aligned}
& \frac{\mathrm{d} \underline{q}_{p-1}^{\mathrm{s}}}{\mathrm{d} t}+\left\{\tau_{p-1}^{-1}-\mathrm{j}\left[\omega_{\mathrm{s}}(t)-(p-1) \cdot \Omega_{\mathrm{m}}(t)\right]\right\} \cdot \underline{q}_{p-1}^{\mathrm{s}}-a_{\mathrm{q}, p-1} \underline{p}_{\mathrm{c}}^{\mathrm{s}}=0 \\
& \frac{\mathrm{d} \underline{q}_{p+1}^{\mathrm{s}}}{\mathrm{d} t}+\left\{\tau_{p+1}^{-1}+\mathrm{j}\left[\omega_{\mathrm{s}}(t)-(p+1) \cdot \Omega_{\mathrm{m}}(t)\right]\right\} \cdot \underline{q}_{p+1}^{\mathrm{s}}-a_{\mathrm{q}, p+1} \underline{p}_{\mathrm{c}}^{\mathrm{s}}=0 \\
& \underline{F}_{\mathrm{e}}^{\mathrm{s}}(t)=k_{\mathrm{q} 0} \underline{p}_{\mathrm{c}}^{\mathrm{r}}+\underline{q}_{p-1}^{\mathrm{s}}+\underline{q}_{p+1}^{\mathrm{s}}
\end{aligned}
$$

where $\underline{q}_{p \pm 1}$ are the new transformed variables, $\omega_{\mathrm{s}}$ is the supply frequency, $\tau_{p \pm 1}$ are the time constants of the harmonic components $p \pm 1$, and $k_{\mathrm{q} 0}$ and $a_{\mathrm{q}, p \pm 1}$ the other parameters of the system. Equation (19), which is derived for the transient 
operation with constant flux, can be reduced in steady-state operation into the form presented by Arkkio et al. (2000) and presented in Equation (12). In circular whirling motion, Equation (19) can be simplified further into the form that closely resembles the analytical equations of UMP presented by Früchtenicht et al. $(1982 a)$.

The force model presented above assumes that the eccentricity force is induced exclusively by the fundamental and eccentricity field components, i.e., by the components $p, p-1$, and $p+1$. Recently, during the preparations for Publication P6, it was observed in the numerical simulations that the higher-order spatial components may contribute remarkably to the eccentricity force in certain types of induction motors. For example, the stator slotting harmonics together with the eccentricity harmonics may induce a significant force component, particularly, if the slots are open. The order of these field components is $Q_{\mathrm{s}}, Q_{\mathrm{s}}-1$, and $Q_{\mathrm{s}}+1$, where $Q_{\mathrm{s}}$ is the number of stator slots. Together, these components induce an eccentricity force. The rotor cage did not reduce these field components effectively because the wavelength was close to the slot pitch of the rotor, and thus the induced force was directed through the shortest air gap. In this context, it is remarkable that these additional forces do not change the form of the FRF (Figure 3). Thus, the same electromagnetic force model can be used in applications, though the physical explanation is not any more valid.

\subsection{Estimation of model parameters}

From the beginning, the electromagnetic force model presented in Publication P4 was intended to be applied together with the numerically estimated parameters. The parametric force model in the constant flux and steady-state operation may be written as 


$$
\begin{aligned}
& \frac{\mathrm{d} \hat{i}_{\mathrm{r}, p-1}^{\mathrm{r}}}{\mathrm{d} t}+\tau_{p-1}^{-1} \underline{i}_{\mathrm{r}, p-1}^{\mathrm{r}}+a_{p-1} \cdot\left(\frac{\mathrm{d} \underline{p}_{\mathrm{c}}^{\mathrm{r}^{*}}}{\mathrm{~d} t}+\mathrm{j} s \omega_{\mathrm{s}} \underline{p}_{\mathrm{c}}^{\mathrm{r}}\right) \cdot \mathrm{e}^{\mathrm{j}\left(s \omega_{\mathrm{s}} t+Q_{\mathrm{b} 0}\right)}=0 \\
& \frac{\mathrm{d} \hat{i}_{\mathrm{r}, p+1}^{\mathrm{r}}}{\mathrm{d} t}+\tau_{p+1}^{-1} \underline{i}_{\mathrm{r}, p+1}^{\mathrm{r}}+a_{p+1} \cdot\left(\frac{\mathrm{d} \underline{p}_{\mathrm{c}}^{\mathrm{r}}}{\mathrm{d} t}+\mathrm{j} s \omega_{\mathrm{s}} \underline{p}_{\mathrm{c}}^{\mathrm{r}}\right) \cdot \mathrm{e}^{\mathrm{j}\left(s \omega_{\mathrm{s}} t+\vartheta_{\mathrm{b} 0}\right)}=0 \\
& \underline{F}_{\mathrm{e}}^{\mathrm{r}}(t)=k_{0} \underline{p}_{\mathrm{c}}^{\mathrm{r}}+c_{p-1} \underline{\hat{i}}_{\mathrm{r}, p-1}^{\mathrm{r}}{ }^{*} \mathrm{e}^{\mathrm{j}\left(s \omega_{\mathrm{s}} t+\vartheta_{\mathrm{b} 0}\right)}+c_{p+1} \underline{\hat{i}}_{\mathrm{r}, p+1}^{\mathrm{r}} \mathrm{e}^{-\mathrm{j}\left(s \omega_{\mathrm{s}} t+\vartheta_{\mathrm{b} 0}\right)}
\end{aligned}
$$

where $s$ is the slip, $\vartheta_{\mathrm{b} 0}$ the phase angle of the magnetic-flux-density space-vector at $t=0, F_{\mathrm{e}}^{\mathrm{r}}$ the total electromagnetic force exerted on the rotor, and, finally, $a_{p \pm 1}, \tau_{p \pm 1}, c_{p \pm 1}$ and $k_{0}$ are the system parameters.

Publication P5 presents an efficient method of estimating the model parameters. The applied method is based on the impulse response method presented by Tenhunen et al. (2003c) and in Publication P3. In this case, the estimation of the parameters is more complicated because the parameters are associated with the rotating cage-current components. The time-dependent spatial distribution of the currents can be described by the space-vectors. Unfortunately, this yields the differential equations (20) including a time-dependent multiplier $\mathrm{e}^{\mathrm{j}\left(s \omega_{\mathrm{s}} t+\vartheta_{b 0}\right)}$. However, it is possible to get rid of this multiplier by transforming the spacevector variables. Finally, the equations for the modified FRFs can be derived, and, by using these, the required parameters can be estimated.

In Publication P5, the $15 \mathrm{~kW}$ motor was used as a numerical example. When the saturation was neglected, the parametric model described almost exactly the behaviour of the numerical simulation model. As expected, the saturation of magnetic materials changes the behaviour of the system. Figure 4 shows the FRF of the cage-current component $p-1$ with saturation included. It appears that the saturation couples the harmonic current components together. 


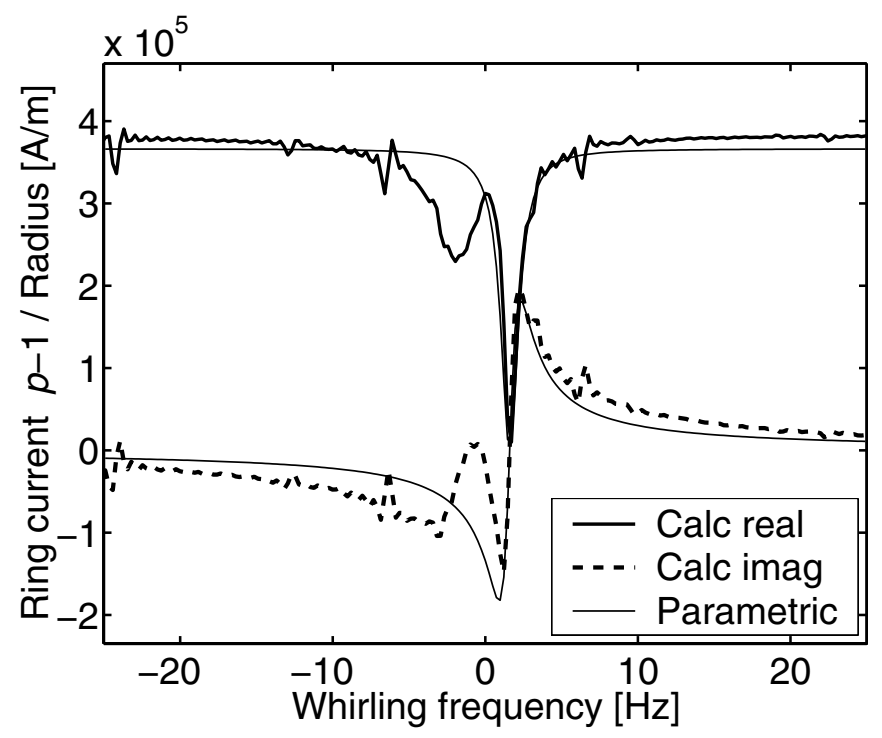

Figure 4. FRF of the $15 \mathrm{~kW}$ motor between the cage current component $p-1$ and rotor motion with saturation included.

The covered frequency range depends on the length and type of the excitation pulse (Ewins 2000). In previous studies, the rotor was moved in one radial direction in the stator reference frame. In Publication P6, a rotating excitation pulse was applied in order to control better the excitation frequency range, and thus excite more effectively the required system modes. In addition, Publication P6 presents the application of the averaging method (Ewins 2000) in order to eliminate the effect of a disturbing unsynchronous force component.

\subsection{Electromechanical rotor model}

A first version of the electromechanical rotor model was presented in Publication P1. This model was the starting point for the developments in all the other publications. The final model, which will be discussed in this overview, was presented in Publication P6. The electromechanical rotor model was obtained by combining the electromagnetic force model based on Equation (19) with the simple Jeffcott rotor model of Equation (1) written in the rotor reference frame (Childs 1993) 


$$
m \cdot \frac{\mathrm{d}^{2} \underline{p}_{\mathrm{c}}^{\mathrm{r}}}{\mathrm{d} t^{2}}+\left(d+\mathrm{j} 2 m \Omega_{\mathrm{m}}\right) \cdot \frac{\mathrm{d} \underline{p}_{\mathrm{c}}^{\mathrm{r}}}{\mathrm{d} t}+\left(k+\mathrm{j} d \Omega_{\mathrm{m}}-m \Omega_{\mathrm{m}}^{2}\right) \cdot \underline{p}_{\mathrm{c}}^{\mathrm{r}}=\Omega_{\mathrm{m}}{ }^{2} m \underline{a}
$$

The electromechanical rotor model in the steady-state operation conditions can be written

$$
\begin{aligned}
& m \cdot \frac{\mathrm{d}^{2} \underline{p}_{\mathrm{c}}^{\mathrm{r}}}{\mathrm{d} t^{2}}+\left(d+\mathrm{j} 2 m \Omega_{\mathrm{m}}\right) \cdot \frac{\mathrm{d} \underline{p}_{\mathrm{c}}^{\mathrm{r}}}{\mathrm{d} t}+\left(k-k_{\mathrm{e}}+\mathrm{j} d \Omega_{\mathrm{m}}-m \Omega_{\mathrm{m}}{ }^{2}\right) \cdot \underline{p}_{\mathrm{c}}^{\mathrm{r}}+ \\
& -c_{p-1} \underline{q}_{p-1}^{\mathrm{r}}-c_{p+1} \underline{q}_{p+1}^{\mathrm{r}}=\Omega_{\mathrm{m}}{ }^{2} m \underline{a} \\
& \frac{\mathrm{d} \underline{q}_{p-1}^{\mathrm{r}}}{\mathrm{d} t}+\left(\tau_{p-1}^{-1}-\mathrm{j} s \omega_{\mathrm{s}}\right) \cdot \underline{q}_{p-1}^{\mathrm{r}}+a_{p-1} \cdot\left(\frac{\mathrm{d} \underline{p}_{\mathrm{c}}^{\mathrm{r}}}{\mathrm{d} t}-\mathrm{j} s \omega_{\mathrm{s}} \underline{p}_{\mathrm{c}}^{\mathrm{r}}\right)=0 \\
& \frac{\mathrm{d} \underline{q}_{p+1}^{\mathrm{r}}}{\mathrm{d} t}+\left(\tau_{p+1}{ }^{-1}+\mathrm{j} s \omega_{\mathrm{s}}\right) \cdot \underline{q}_{p+1}^{\mathrm{r}}+a_{p+1} \cdot\left(\frac{\mathrm{d} \underline{p}_{\mathrm{c}}^{\mathrm{r}}}{\mathrm{d} t}+\mathrm{j} s \omega_{\mathrm{s}} \underline{p}_{\mathrm{c}}^{\mathrm{r}}\right)=0
\end{aligned}
$$

where the first row is the modified mechanical equation of motion, and the two last rows represent the governing differential equations for the essential cagecurrent components. To generalise the results and observations, the electromechanical rotor model of Equation (20) was transformed into a dimensionless form

$$
\begin{aligned}
& \frac{\mathrm{d}^{2} \underline{\tilde{p}}_{\mathrm{c}}^{\mathrm{r}}}{\mathrm{d} \tilde{t}^{2}}+2\left(\zeta+\mathrm{j} R_{\omega}\right) \frac{\mathrm{d} \underline{\tilde{p}}_{\mathrm{c}}^{\mathrm{r}}}{\mathrm{d} \tilde{t}}+\left(1-\alpha+\mathrm{j} 2 \zeta R_{\omega}-R_{\omega}^{2}\right) \underline{\tilde{p}}_{\mathrm{c}}^{\mathrm{r}}-\underline{\tilde{q}}_{p-1}^{\mathrm{r}}-\underline{\tilde{q}}_{p+1}^{\mathrm{r}}=R_{\omega}^{2} \underline{\tilde{a}} \\
& \frac{\mathrm{d} \underline{\tilde{q}}_{p-1}^{\mathrm{r}}}{\mathrm{d} \tilde{t}}+\left(\tilde{\tau}_{p-1}^{-1}-\mathrm{j} \gamma R_{\omega}\right) \cdot \underline{\tilde{q}}_{p-1}^{\mathrm{r}}+\alpha \tilde{c}_{p-1} \cdot\left(\frac{\mathrm{d} \underline{\tilde{p}}_{\mathrm{c}}^{\mathrm{r}}}{\mathrm{d} \tilde{t}}-\mathrm{j} \gamma R_{\omega} \underline{\tilde{p}}_{\mathrm{c}}^{\mathrm{r}}\right)=0 \\
& \frac{\mathrm{d} \underline{\tilde{q}}_{p+1}^{\mathrm{r}}}{\mathrm{d} \tilde{t}}+\left(\tilde{\tau}_{p+1}^{-1}+\mathrm{j} \gamma R_{\omega}\right) \cdot \underline{\tilde{q}}_{p+1}^{\mathrm{r}}+\alpha \tilde{c}_{p+1} \cdot\left(\frac{\mathrm{d} \tilde{\tilde{p}}_{\mathrm{c}}^{\mathrm{r}}}{\mathrm{d} \tilde{t}}+\mathrm{j} \gamma R_{\omega} \underline{\tilde{p}}_{\mathrm{c}}^{\mathrm{r}}\right)=0
\end{aligned}
$$

where $R_{\omega}=\Omega_{\mathrm{n}} / \omega_{\mathrm{n}}$ is the speed ratio, $\omega_{\mathrm{n}}=\sqrt{k / m}$ the natural flexural frequency of the rotor without electromagnetic interaction, $\alpha=k_{\mathrm{e}} / k$ the ratio between the apparent electromagnetic stiffness and the shaft stiffness, $\zeta$ the factor for external viscous damping, $\gamma=p s /(1-s)$ the shorthand notation associated with the slip and the number of pole-pairs, and the tilde above a symbol denotes the di- 
mensionless parameter (Publication P6). Thus, the electromechanical rotor model and characteristic dynamical behaviour of an arbitrary machine can be described by a set of eight real valued dimensionless parameters.

The purely mechanical Jeffcott rotor model includes the forward and backward whirling modes. The electromechanical force model increases the total number of modes by two. In principle, all the modes of the electromechanical rotor model are coupled electromechanical modes. However, the interaction between the mechanical and electrical system is strong only when the rotor rotational speed is close to the first flexural critical speed. In that case, the originally electromagnetic modes may couple with the forward whirling mode.

Figures 5-8 present some numerical results calculated for two large induction motors: a two-pole 2.6 MW, and a four-pole 4.2 MW motor. Figures 5 and 6 show the dimensionless eigenfrequencies and decay-constants as functions of the speed ratio. The dimensionless eigenfrequencies and decay constants are obtained by dividing the dimensional counterparts by $\omega_{\mathrm{n}}$. The mechanical damping is assumed to be zero in order to better distinguish the electromagnetic effects.

As can be seen in Figure 6, the electromechanical interaction may destabilise one of the modes, and thus the whole rotordynamic system. The stability is achieved by including the non-rotating damping into the model. The minimum damping value needed to eliminate the destabilising force on the entire speed range is $\zeta=0.022$ for the $4.2 \mathrm{MW}$ motor. To reveal the effect of different parameters on the stability, it is possible to plot so-called stability charts. Figure 7 shows, as an example, a stability chart based on the fixed parameters of the 2.6 MW motor. Most of the previously presented stability charts include the internal damping of the rotor as an essential parameter (Geysen et al. 1979, Früchtenicht et al. 1980, 1982b). It is well known that the internal rotor damping may unstabilise the system over the supercritical operation range (e.g. Childs 1993). The current model offers a natural explanation for rotordynamic instability without any assumption of internal rotor damping. 


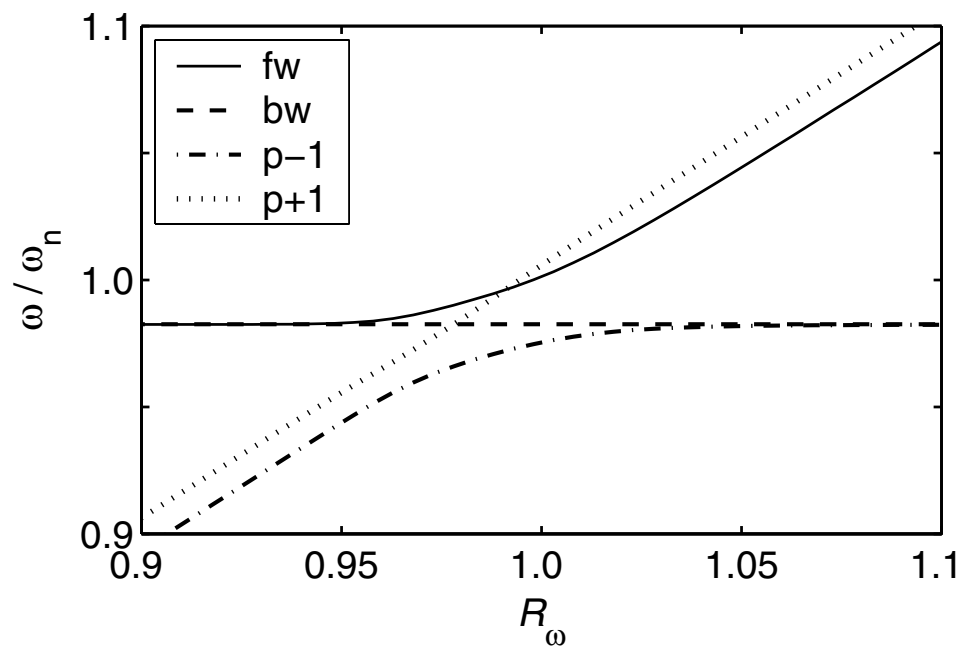

Figure 5. Dimensionless eigenfrequencies of the 4.2 MW four-pole motor as a function of the speed ratio in the stator reference frame. The labels of the modes are connected to the forward whirling (fw), backward whirling (bw), and the cage-current components $p \pm 1$ at the lower end of the rotation speed.

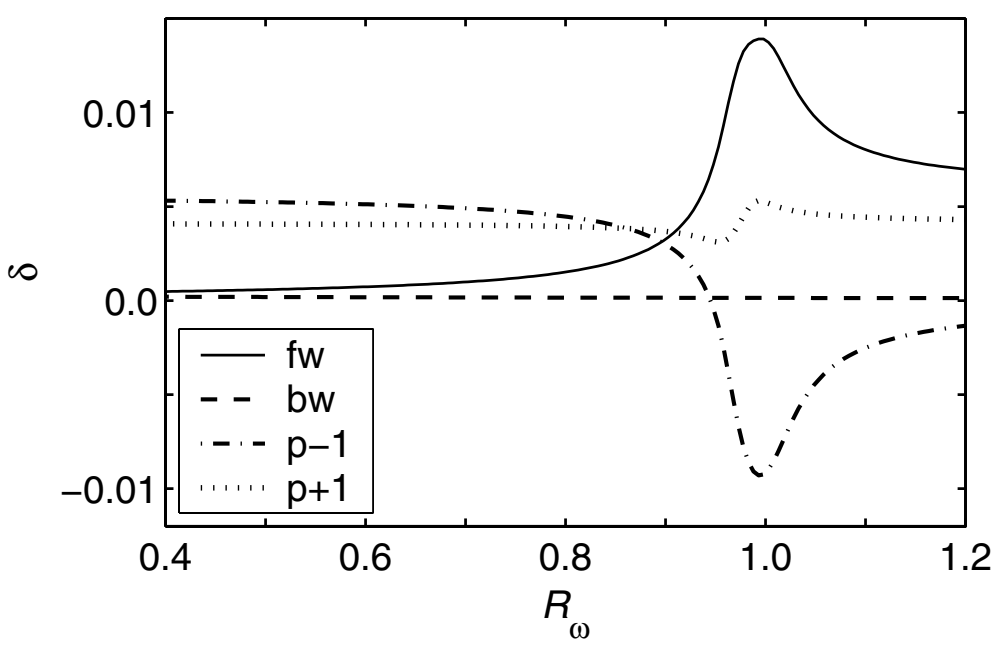

Figure 6. Dimensionless decay constants of the 4.2 MW four-pole motor as a function of the speed ratio. 


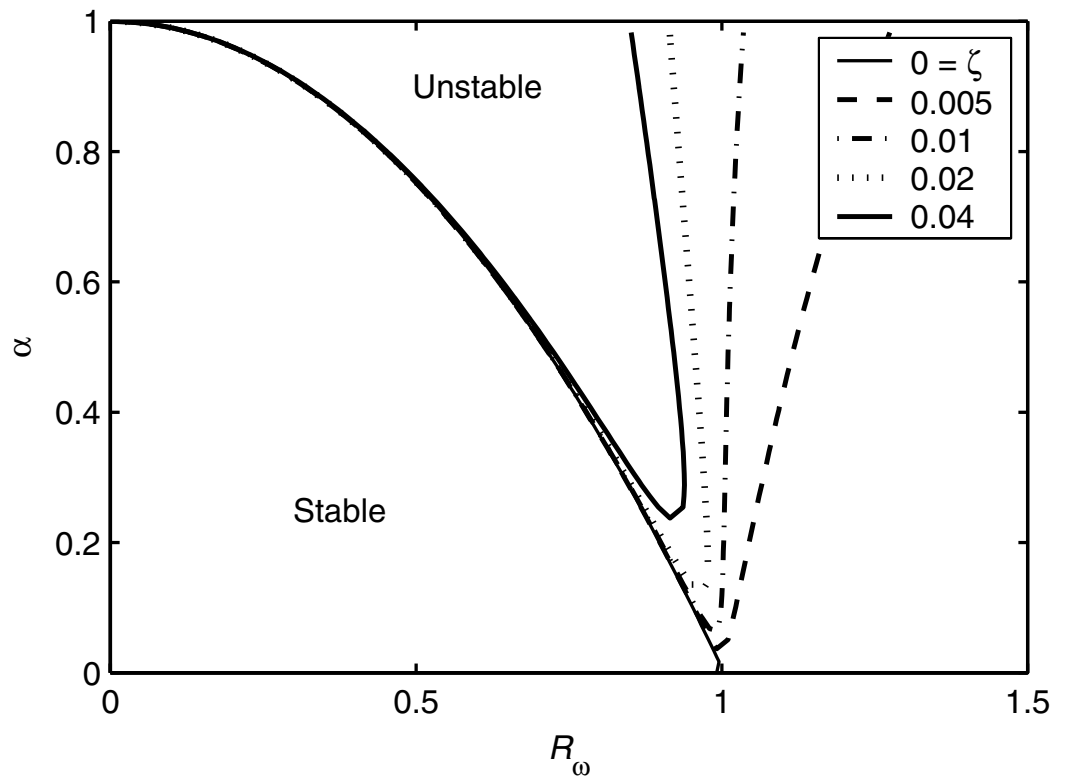

Figure 7. Stability chart for the speed ratio $\left(R_{\omega}\right)$, force ratio $(\alpha)$, and external viscous damping $(\zeta)$. The reference point is taken from the parameters of the 2.6 MW motor: $\tilde{c}_{p+1}=0.623, \tilde{\tau}_{p+1}=162$.

Figure 8 shows an example of the amplification factor due to the mass unbalance. The parameters of the system correspond to those of the $2.6 \mathrm{MW}$ motor. According to Figure 7, the electromechanical interaction reduces effectively the unbalance response close to the critical speed.

In conclusion, the electromechanical interaction decreases the natural frequencies of the rotor. This effect is known as the electromagnetically induced negative spring constant (e.g., Freise \& Jordan 1962, Früchtenicht et al. 1982a-b). At subcritical rotational speeds, the mechanical vibration energy of all modes is dissipated via resistive losses of the rotor and stator currents. At supercritical rotational speeds, the effects are qualitatively similar with the exception of one mode that receives energy from the electrical system. If the mechanical energy dissipation of this mode is too small, a form of self-excited vibrations may follow leading to the rotordynamic instability. Because this instability is induced by the periodic variation of the system parameters, this phenomenon is one form of the parametric instability. Excluding the potential rotordynamic instability, the 
numerical results indicate that the electromechanical interaction reduces effectively the unbalance response close to the first flexural critical speed.

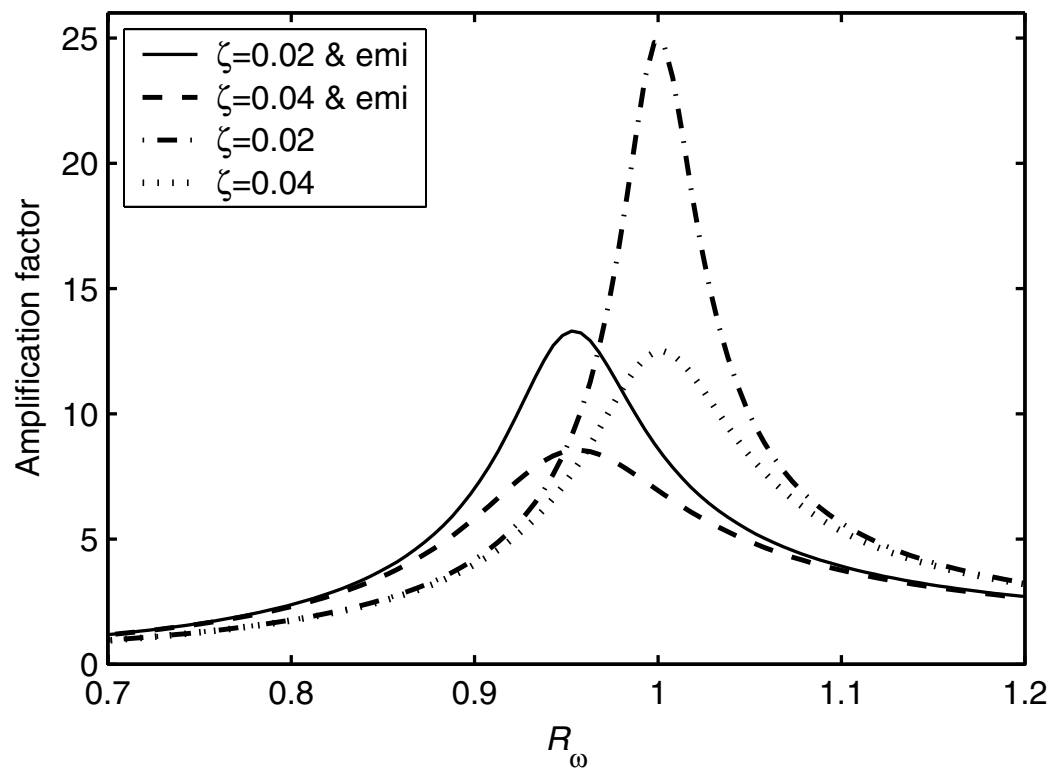

Figure 8. Amplification factor due to the mass unbalance. The amplification factor using two different non-rotating damping factors are calculated together with electromechanical interaction (emi) or without it. The other parameters are taken from the 2.6 MW two-pole induction motor: $\alpha=0.111, \tilde{c}_{p+1}=0.623$, $\tilde{\tau}_{p+1}=162$.

\subsection{Verification of the electromagnetic force and electromechanical rotor model}

The electromagnetic force model was verified against more complete finite element models in Publication P5. The simple parametric model yielded for the 15 $\mathrm{kW}$ motor results that were almost identical with the numerical model when the saturation of magnetic materials was ignored. In this case, the estimated model parameters were almost independent of the operation condition. This indicates that the form of the simple equations is right. As expected, the saturation of magnetic materials changed the behaviour of the system. Even so, the parametric 
model together with the estimated parameters predicts the system behaviour fairly accurately for an arbitrary steady-state operation condition.

The electromagnetic force model of Equation (11), which has the same form as the force model of Equation (19) in the whirling motion and steady-state conditions, was validated by Arkkio et al. (2000). In that study, the numerical and experimental results for the $15 \mathrm{~kW}$ motor in no-load condition correlated excellently. Similarly, the expanded electromagnetic force model for the conical whirling motion was validated experimentally by Tenhunen et al. (2003a, 2003b).

The electromechanical rotor model was verified similarly against more complete electromechanical finite element models. The comparison results are presented in Publications P2 and P3. One way to compare the models is to plot the response signals induced by the same excitation. Figure 9 shows an example in which the rotor of the $18 \mathrm{~kW}$ motor was excited by a horizontal impulse force.

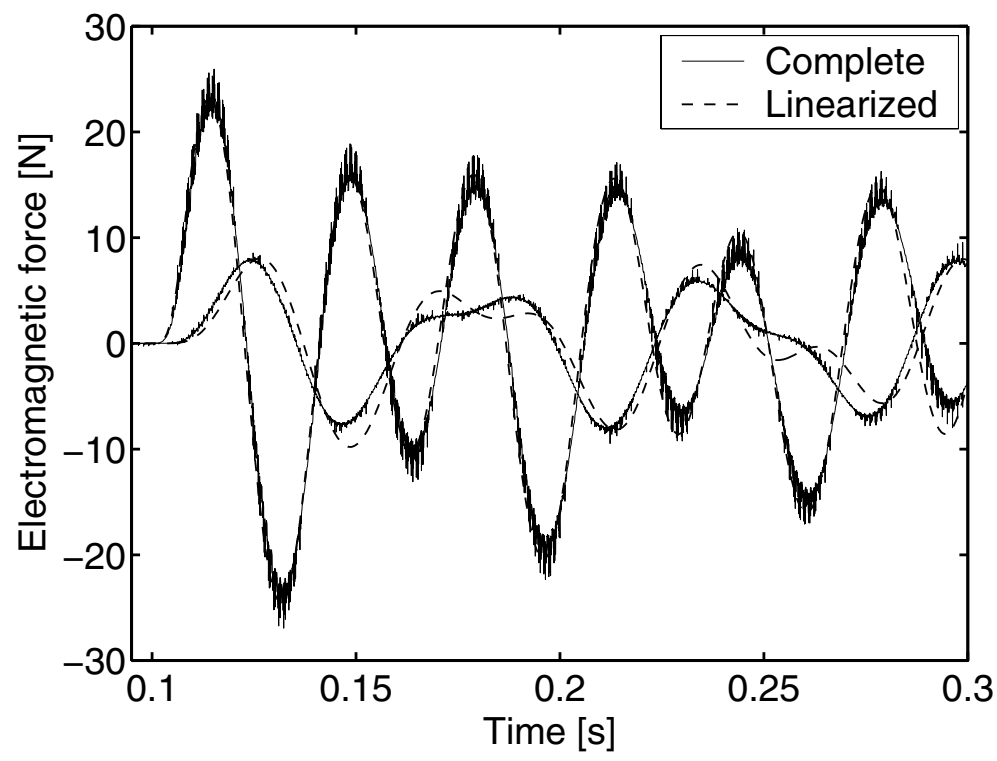

Figure 9. The electromagnetic force of the $18 \mathrm{~kW}$ motor induced by the horizontal mechanical impulse. The results obtained by the complete and linearised electromechanical models. The amplitude of the horizontal component is larger. 
Another, more comprehensive, way to study the similarity of the two system models is to compare the FRFs. Figure 10 shows the amplitude of the FRF between the rotational displacement response and the rotational excitation force.

In conclusion, the simple electromagnetic force model and the electromechanical rotor model predict fairly well the essential behaviour of the system at low frequency range. In addition, it can be underlined that the computational resources, required by the simple models, are only a small fraction of those required by the complete non-linear finite-element models.

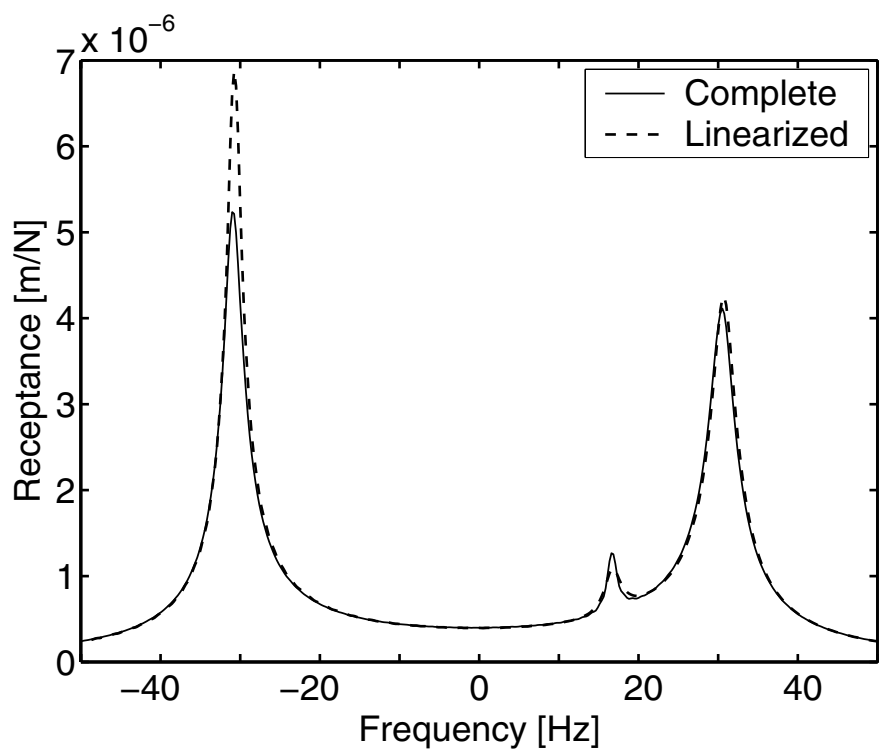

Figure 10. The amplitude of the FRF between the whirling amplitude and rotational excitation force.

Holopainen et al. (2004) made a series of experiments to validate the electromechanical rotor model. They equipped a standard six-pole $18 \mathrm{~kW}$ cage induction motor with a long flexible shaft. The frequency and damping ratio of the first flexural mode was identified in unloaded steady-state operation. The electromagnetic interaction was varied by changing the supply current and frequency. The obtained results showed clearly the effects of electromechanical interaction. At low supply frequencies, the electromagnetic fields appeared to dampen the rotor vibrations effectively. The higher the supply voltage, the 
stronger the damping effect. At higher supply frequencies, the electromagnetic fields appeared to transfer energy into the mechanical system. This led to the limit-cycle vibrations and sub-critical instability when the supply voltage was increased. In addition, the stability limit was determined as a function of supply current and frequency. 


\section{Discussion}

A new simple electromechanical rotor model was presented to assess the effects of electromechanical interaction in rotordynamics of cage induction motors. The model was obtained by combining the Jeffcott rotor model with the simple electromagnetic force model. The applied force model is an extension of the model presented by Arkkio et al. (2000). The parameters and variables of this model have a clear physical meaning and it can be used in transient operation conditions. An effective method was presented to estimate the parameters of this electromagnetic force model from the numerical simulation of an impulse response. The presented method is computationally very efficient compared to the forced whirling method (Arkkio et al. 2000) used previously. The parameters of the force model are functions of the operation condition due to the saturation of magnetic materials. However, the parameters are relatively constant in the socalled constant flux operation, which commonly covers a remarkable part of the operation conditions.

The purely mechanical Jeffcott rotor model includes the forward and backward whirling modes. The electromagnetic force model increases the total number of modes by two. In principle, all the modes of the electromechanical rotor model are coupled electromechanical modes. However, the interaction between the mechanical and electrical system is strong only when the rotor rotational speed is close to the first flexural critical speed. In that case, the originally electromagnetic modes may couple with the forward whirling mode.

The results obtained show that the electromechanical interaction may decrease the natural frequencies of the rotor, induce additional damping or cause rotordynamic instability. These interaction effects are most significant in motors operating at, or close to, the first flexural critical speed. Excluding the potential rotordynamic instability, the numerical results indicate that the electromechanical interaction reduces effectively the unbalance response close to the first flexural critical speed.

The developed electromechanical rotor model differs from its predecessors, because it includes two additional variables for the harmonic currents of the rotor cage. The prevailing approach of other researchers has been to include the electromechanical interaction in the form of additional electromagnetic stiffness 
and damping coefficients without additional variables. The simulation results of Figure 2 show that the electromagnetic force exerted on the rotor in an arbitrary rotor motion cannot be described by a model including only the displacementand velocity-dependent terms. In this study, two essential components $(p \pm 1)$ of the harmonic rotor currents are used as additional variables in the electromagnetic force and the electromechanical rotor model.

The form of the analytical equations for the electromagnetic force presented by Früchtenicht et al. (1982a) is similar to the form of the simple force model by Arkkio et al. (2000) when the rotor is whirling in a circular path at constant speed. It was significant, that Arkkio et al. (2000) transformed the force model of whirling motion into the form of arbitrary rotor motion. They applied a mathematical transformation together with certain assumptions. This introduced two additional variables without any clear physical meaning. In this study, this missing physical explanation was researched, and the analytical equations thereby related to the numerical simulation results.

The introduced additional variables of the electromagnetic force model can be included straightforwardly into the electromechanical force model. Moreover, that leads to a new type of coupled equations and offers a better-founded explanation for the effects of electromechanical interaction.

The electromagnetic field exerts a force on the rotor. The force component parallel to the rotor motion is called the tangential component. This component can decrease or increase the mechanical energy of the rotor depending on the direction. The latter alternative can lead to rotordynamic instability. There are several rotordynamic mechanisms, which induce damping or destabilising forces exerted on the rotor. Many of them appear as skew-symmetric terms in the stiffness matrix. This means that the force is determined completely by the deflection of the rotor. Typical reasons for the skew-symmetry are the hydrodynamic bearings, internal friction, rotor anisotropy, and seals. The effects of electromechanical interaction are similar to the effects of these phenomena: additional damping or rotordynamic instability. However, the presented model of electromechanical interaction includes two additional variables, which are needed to model the state of the electromagnetic system. This electromagnetic system is described by two simple differential equations. Thus, the electromechanical interaction cannot 
be reduced into the form of a skew symmetric stiffness matrix without a high degree of approximation.

In this study, the rotor core was assumed to be rigid and perfectly aligned with the rigid stator bore. These assumptions enabled the use of the two-dimensional electromagnetic models, but likewise, restricted the mechanical rotor model and induced vibrations to be symmetric. Secondly, the homopolar flux may affect remarkably the rotordynamic behaviour of flexible-shaft two-pole motors (Belmans et al. 1987, Belmans 1994). However, in this study, the homopolar flux was ignored in the estimation of electromechanical force parameters. Thirdly, the presented results are limited to the cage induction motors without parallel paths in the stator windings. It is assumed that the parallel paths affect the interaction forces by enabling circulatory currents in the stator winding to resemble the effects of rotor-cage currents. Fourthly, only the low-order components of the eccentricity harmonics $p \pm 1$ were included in the parametric force model. The high-order components may induce significant force components, particularly at higher frequencies.

The presented rotordynamic model is suitable for practical applications in industry. The parameter values of a motor can be estimated from the design data, or, if better accuracy is required, from the numerical simulation results, as was the case in this study. After that, the effects of electromechanical interaction can be easily assessed. It appears that the prevailing industrial practice is to apply the negative spring constant estimated by Equation (13). According to the present study, the interaction cannot be modelled by additional stiffness and damping constants, especially if accuracy over the wide frequency range, including the critical speed, is required. It appears that the formula of Equation (13) is a relatively good estimate, if the critical speed is approximated. However, it clearly overestimates the negative spring constant outside of the critical speed range where the equalising currents are acting. The risk of rotordynamic instability has been known for a long time, and several cases have been reported in the literature (Krondl 1956, Kellenberger 1966, Haase 1973, Haase et al. 1973). However, the positive effect of electromechanical interaction inducing additional damping close to the critical speed seems to be unnoticed in research literature and industrial applications. 
This study contains only a minor sub-area of an exciting field of research. It appears that there are needs and prospects for further research focused on the effects of a) the parallel paths in the stator windings, b) the high-order components (e.g., those induced by stator slotting) on the electromagnetic force model, c) the homopolar flux in flexible-shaft two-pole machines, and d) the ovalisation modes of the stator on the electromechanical interaction. 


\section{Conclusions}

A new simple electromechanical rotor model was presented to assess the effects of electromechanical interaction in the rotordynamics of cage induction motors. The model was obtained by combining the Jeffcott rotor model with the developed electromagnetic force model. The parameters and variables of this model have a clear physical meaning. An effective method was presented to estimate the parameters of this model from the numerical simulation of an impulse response. The parameters are a function of the operation condition due to the saturation of magnetic materials. However, the parameters are relatively constant in the so-called constant flux operation, which commonly covers a remarkable part of the operation conditions.

The developed electromechanical rotor model differs from its predecessors in that it includes two additional variables for the harmonic currents of the rotor cage. The prevailing approach of other researches has been to include the electromechanical interaction in the form of additional electromagnetic stiffness and damping coefficients without additional variables.

The obtained results show that the electromechanical interaction may decrease the natural frequencies of the rotor, induce additional damping or cause rotordynamic instability. These interaction effects are most significant in a motor operating at, or close to, the first flexural critical speed. Excluding the potential rotordynamic instability, the numerical results indicate that the electromechanical interaction effectively reduces the unbalance response close to the first flexural critical speed. 


\section{References}

Amati, N. \& Brusa, E. 2001. Vibration condition monitoring of rotors on AMB fed by induction motors. In: Proceedings of the 2001 IEEE/ASME International Conference on Advanced Intelligent Mechatronics. Como, Italy, 8-12 July, 2001. Vol. 2. Pp. $750-756$.

Amrhein, W., Silber, S., Nenninger, K., Trauner, G., Reisinger, M. \& Schoeb, R. 2003. JSME International Journal, Series C: Mechanical Systems, Machine Elements and Manufacturing. Vol. 46, No. 2, pp. 343-348.

Arkkio, A. \& Lindgren, O. 1994. Unbalanced magnetic pull in a high-speed induction motor with an eccentric rotor. In: Proceedings of the International Conference on Electrical Machines 1994. Paris, France, 5-8 September, 1994. Vol. 1. Pp. 53-58.

Arkkio, A. 1996. Unbalanced magnetic pull in cage induction motors - dynamic and static eccentricity. In: Proceedings of the International Conference on Electrical Machines 1996. Vigo, Spain, 10-12 September, 1996. Vol. 1. Pp. 192-197.

Arkkio, A., Antila, M., Pokki, K., Simon, A. \& Lantto, E. 2000. Electromagnetic force on a whirling cage rotor. IEE Proceedings - Electric Power Applications, Vol. 147. Pp. 353-360.

Baoguo, W. \& Fengxiang, W. 2001. Modeling and analysis of levitation force considering air-gap eccentricity in a bearingless induction motor. In: Proceedings of the $5^{\text {th }}$ International Conference on Electrical Machines and Systems, 2001. Shenyang, China, 18-20 August, 2001. Vol. 2. Pp. 934-937.

Baumgardner, J. 1994. Vibration in squirrel-cage induction motors. In: Proceedings of the $12^{\text {th }}$ Annual Meeting, Vibration Institute Nashville, Tennessee. Pp. 179-183. 
Belmans, R. 1984. Radiale trillingen van driefasige, tweepolige inductiemachines met kooianker (Radial vibrations of three-phase, two-pole induction machine with squirrel cage). Leuven: Katholieke Universiteit Leuven. 325 p. (Doctoral thesis)

Belmans, R., Heylen, A., Vandenput, A. \& Geysen, W. 1984a. Influence of rotor-bar stiffness on the critical speed of an induction motor with an aluminium squirrel cage. IEE Proceedings, Vol. 131, Part B, No. 5. Pp. 203-208.

Belmans, R., Zeebroek, G. \& Geysen, W. 1984b. Influence of the electromagnetical phenomena on the radial vibrations of a two-pole induction motor with squirrel cage rotor. In: Proceedings of International Conference on Electrical Machines (ICEM-84). Lausanne, Switzerland, 18-21 September, 1984. Pp. 695-699.

Belmans, R., Vandenput, A. \& Geysen, W. 1987. Influence of unbalanced magnetic pull on the radial stability of flexible-shaft induction machines. IEE Proceedings, Vol. 134, Part B, No. 2. Pp. 101-109.

Belmans, R. 1994. Recent major developments in CAE and vibrations and audible noise analysis of rotating electrical machines. Leuven: Garant Publishers. 212 p. ISBN 90-5350-333-1

Benaragama, D. S., Ward, D. M. \& Tavner, P. J. 1982. Unbalanced magnetic pull on the eccentric rotor of a turbo-generator. In: Proceedings of the International Conference on Electrical Machines 1982. Budapest, Hungary, 5-9 September, 1982. Pp. 922-925.

Bettig, B. P. \& Han, R. P. S. 1999. Modeling the lateral vibration of hydraulic turbine-generator rotors. Journal of Vibration and Acoustics, Vol. 121, No. 3, pp. 322-327.

Bressani, M., Odorico, A. \& Sica, M. 1993. High-speed, large-power induction motors for direct coupling to variable-speed gas compressors. In: Proceedings of the $5^{\text {th }}$ European Conference on Power Electronics and Applications. Brighton, England, 13-16 September, 1993. Pp. 366-371. 
Brosch, P. F., Früchtenicht, J. \& Jordan, H. 1974. Laufruhestörungen bei elektrischen Maschinen. Konstruktion im Maschinen-, Apparate- und Gerätebau, Vol. 26, No. 3, pp. 107-111.

Cai, J. \& Henneberger, G. 2001. Transient FEM computation of radial force and torque for bearingless wound-rotor induction motors. In: Proceedings of the $5^{\text {th }}$ International Conference on Electrical Machines and Systems, 2001. Shenyang, China, 18-20 August, 2001. Vol. 2. Pp. 991-994.

Chaban, V. I., Kharchenko, Ye., V. \& Kozubash, V. I. 1990. An algorithm for calculating the vibration characteristics of an induction motor rotor. Electric Technology U.S.S.R., No. 1, pp. 34-43 (Translated from Elektrichestvo, 1990, No. 1, pp. 71-75)

Chiba, A., Power, D. T. \& Rahman, M. A. 1991a. Characteristics of a bearingless induction motor. IEEE Transactions on Magnetics, Vol. 27, No. 6, pp. 5199-5201.

Chiba, A., Power, D. T. \& Rahman, M. A. 1991b. No load characteristics of a bearingless induction motor. In: Proceedings of the 1991 IEEE Industry Applications Society Annual Meeting (Part 1). Dearborn, MI, USA, 28 September 4 October, 1991. Pp. 126-132.

Chiba, A., Deido, T., Fukao, T. \& Rahman, M. A. 1994. An analysis of bearingless AC motors. IEEE Transactions on Energy Conversion, Vol. 9, No. 1, pp. 61-68.

Childs, D. 1993. Turbomachinery rotordynamics: phenomena, modeling, and analysis. New York: John Wiley \& Sons. 476 p. ISBN 0-471-53840-X

DeBortoli, M. J., Salon, S. J., Burow, D. W. \& Slavik, C. J. 1993. Effects of rotor eccentricity and parallel windings on induction machine behavior: a study using finite element analysis. IEEE Transactions on Magnetics, Vol. 29, No. 2, pp. 1676-1682.

Dorrell, D. G. 1993. Calculation of unbalanced magnetic pull in cage induction machines. Cambridge: University of Cambridge. 169 p. (Doctoral thesis) 
Dorrell, D. G. \& Smith, A. C. 1994. Calculation of UMP in induction motors with serials or parallel winding connections. IEEE Transactions on Energy Conversion, Vol. 9, No. 2, pp. 304-310.

Dorrell, D. G. 1996. Calculation of unbalanced magnetic pull in small cage induction motors with skewed rotors and dynamic rotor eccentricity. IEEE Transactions on Energy Conversion, Vol. 11, No. 3, pp. 483-488.

Dorrell, D. G. \& Smith, A. C. 1996. Calculation and measurement of unbalanced magnetic pull in cage induction motors with eccentric rotors. Part 2: Experimental investigation. IEE Proceedings - Electric Power Applications, Vol. 143, No. 3. Pp. 202-210.

Ewins, D. J. 2000. Modal testing: theory, practice and application. 2. ed. Hertfordshire: Research Studies Press. 562 p. ISBN 0-86380-218-4

Finley, R. F., Hodowanec, M. M. \& Holter, W. G. 2000. An analytical approach to solving motor vibration problems. IEEE Transactions on Industry Applications, Vol. 36, No. 5, pp. 1467-1480.

Freise, W. 1961. Über die kritischen Drehzalen elektrischer Maschinen. Hannover: Technischen Hochschule Hannover. 86 p. (Doctoral thesis)

Freise, W. \& Jordan, H. 1962. Einseitige magnetische Zugkräfte in Drehstrommaschinen. ETZ: elektrotechnische Zeitschrift. Ausgabe A., Vol. 83, pp. 299-303.

Früchtenicht, J., Jordan, H. \& Seinsch, H. O. 1980. Über elektromagnetische Ursachen von Laufruhestörungen in Antrieben mit Induktionsmotoren. Abhandlungen der Braunschweigischen wissenschaftlichen Gesellschaft, Vol. 31, pp. $57-72$.

Früchtenicht, J., Jordan, H. \& Seinsch, H. O. 1982a. Exzentrizitätsfelder als Ursache von Laufinstabilitäten bei Asynchronmaschinen, Teil 1: Elektromagnetische Federzahl und elektromagnetische Dämpfungskonstante. Archiv für Electrotechnik, Vol. 65, pp. 271-281. 
Früchtenicht, J., Jordan, H. \& Seinsch, H. O. 1982b. Exzentrizitätsfelder als Ursache von Laufinstabilitäten bei Asynchronmaschinen, Teil 2: Selbsterregte Biegeeigenschwingungen des Läufers. Archiv für Electrotechnik, Vol. 65, pp. 283-292.

Föppl, A. 1895. Das Problem der Laval'schen Turbinenwelle. Der Civilingenieur, Vol. 41, pp. 333-342.

Geysen, W., Jordan, H., Lohaus, W., von Soós, K., Vandenput, A. \& Walcarius, H. 1979. Disturbances in the behaviour of alternating-current machines by selfexcited electromagnetic phenomena. Electric Power Applications, Vol. 2, No. 3 , pp. 81-86.

Guo, D., Chu, F. \& Chen, D. 2002. The unbalanced magnetic pull and its effects on the vibration in a three-phase generator with eccentric rotor. Journal of Sound and Vibration, Vol. 254, No. 2, pp. 297-312.

Ha, K.-H., Hong, J.-P., Kim, G.-T. 1999. Mechanical vibration and stress analysis of the link of interior permanent magnet type synchronous motor. In: Proceedings of the IEEE International Electric Machines and Drives Conference. Seattle, WA, USA, 9-12 May, 1999. Pp. 150-152.

Ha, K.-H., Hong, J.-P., Kim, G.-T., Chang, K.-C. \& Lee, J. 2000. Orbital analysis of rotor due to electromagnetic force for switched reluctance motor. IEEE Transactions on Magnetics, Vol. 36, No. 4, pp. 1407-1411.

Ha, K.-H. \& Hong, J.-P. 2001. Dynamic rotor eccentricity analysis by coupling electromagnetic and structural time stepping FEM. IEEE Transactions on Magnetics, Vol. 37, No. 5, pp. 3452-3455.

Haase, H. 1973. Über die Störung der Laufruhe von Drehstromasynchronmaschinen infolge elektromagnetischer Anfachungen. Hannover: Technischen Universität Hannover. 51 p. (Doctoral thesis)

Haase, H., Jordan, H. \& Kovács, K. P. 1973. Störung der Laufruhe von Drehstrom-Asynchronmotoren infolge elektromagnetischer Anfachungen. ETZ: elektrotechnische Zeitschrift. Ausgabe A, Vol. 94, No. 2, pp. 73-76. 
Hamer, P. S., Wood, B. M., McClurg, J. J. \& Billington, W. L. 1995. Large 3600 $\mathrm{r} /$ min induction motors operating below their first system resonant speed. IEEE Transactions on Industry Applications, Vol. 31, No. 5, pp. 1177-1185.

He, Y. \& Nian, H. 2003. In: Proceedings of the $5^{\text {th }}$ International Conference on Power Electronics and Drive Systems, 2003. 17-20 November, 2003. Vol. 1. Pp. 242-246.

Heller, B. \& Hamata, V. 1977. Harmonic field effects in induction machines. Amsterdam: Elsevier Scientific Publishing Company. 330 p.

Holopainen, T. P., Aatola, S. \& Arkkio, A. 2004. Vibration measurements for validation of electromechanical rotor model for cage induction motor. Eighth International Conference on Vibrations in Rotating Machinery. Swansea, Wales, 7-9 September, 2004. 10 p. In press.

Iwata, Y. \& Sato, H. 1997. Vibration of rotor in induction motor. In: Proceedings of Asia-Pacific Vibration Conference '97. Kyongju, Korea, 9-13 November, 1997. Pp. 242-246.

Iwata, Y., Sato, H., Komatsuzaki, T. \& Saito, T. 2001. Vibration of induction motor rotor in rotating magnetic field. JSME International Journal, Series C: Mechanical Systems, Machine Elements and Manufacturing, Vol. 44, No. 3, pp. 603-609.

Jeffcott, H. H. 1919. The lateral vibration of loaded shafts in the neighbourhood of a whirling speed - the effect of want of balance. London, Edinburgh and Dublin philosophical magazine and journal of science, Vol. 6:27, pp. 304-314.

Joksimovic, G. M, Durovic, M. D., Penman, J. \& Arthur, N. 2000. Dynamic simulation of dynamic eccentricity in induction machines - winding function approach. IEEE Transactions on Energy Conversion, Vol. 15, No. 2, pp. 143-148.

Kellenberger, W. 1966. Der magnetische Zug in Turbogenerator-Rotoren als Ursache einer Instabilität des mechanischen Laufes. Archiv für Electrotechnik, Vol. 50, No. 4, pp. 253-265. 
Kim, T.-J., Hwang, S.-M. \& Park, N.-G. 2000. Analysis of vibration for permanent magnet motors considering mechanical and magnetic coupling effects. IEEE Transactions on Magnetics, Vol. 36, No. 4, pp. 1346-1350.

Kim, T.-J., Hwang, S.-M., Kim K.-T., Jung, W.-B. \& Kim, C. U. 2001a. Comparison of dynamic responses for IPM and SPM motors by considering mechanical and magnetic coupling. IEEE Transactions on Magnetics, Vol. 37, No. 4, pp. 2818-2820.

Kim, K.-T, Kim K.-S., Hwang, S.-M., Kim K.-T. \& Jung, Y.-H. 2001b. Comparison of magnetic forces for IPM and SPM motor with rotor eccentricity. IEEE Transactions on Magnetics, Vol. 37, No. 5, pp. 3448-3451.

Kiryu, K., Chiba, A. \& Fukao, T. 2001. In: Conference Record of the 2001 IEEE Industry Applications Conference, 2001. Chicago, IL, USA, 30 September 4 October, 2001. Vol. 1. Pp. 64-69.

Kovács, K. P. 1977. Two-pole induction-motor vibrations caused by homopolar alternating fluxes. IEEE Transactions on Power Apparatus and Systems, Vol. PAS-96, No. 4, pp. 1105-1108.

Kovács, P. K. 1984. Transient phenomena in electrical machines. Amsterdam: Elsevier Science Publishers. 391 p. ISBN 0-444-99663-X

Krondl, M. 1956. Selbsterregte Rüttelschwingungen von Induktionsmaschinen mit parallelen Wicklungszweigen. Bulletin des Schweizerischen Elektrotechnischen Vereins, Vol. 47, No. 13, pp. 581-588.

Mansoor, A. 2002. Understanding AC induction motor vibration. Hydrocarbon Processing, Vol. 81, No. 3, pp. 71-78.

McClurg, J. J., Wylie, C. \& Donner, G. 2003. Design, building, testing and commissioning of a large 4-pole induction motor to vibration levels $50 \%$ of API 541. In: Record of Conference Papers - Annual Petroleum and Chemical Industry Conference. Houston, TX, USA, 15-17 September, 2003. Pp. 287-295. 
McSharry, J. P., Hamer, P. S, Morrison, D., Nessa, J. \& Rigsby, J. G. 1998. Design, fabrication, back-to-back test of 14200-hp two-pole cylindrical-rotor synchronous motor for ASD application. IEEE Transactions on Industry Applications, Vol. 34, No. 3, pp. 526-533.

Merrill, E. F. 1994. Dynamics of AC electrical machines. IEEE Transactions on Industry Applications, Vol. 30, No. 2, pp. 277-285.

Müller, G. 1985. Elektrische Maschinen - Betriebsverhalten rotierender elektrischer Maschinen. Berlin: VEB Verlag Technik. 548 p.

Owen, E. L. 1991. Flexible shaft versus rigid shaft electric machines for petroleum and chemical plants. IEEE Transactions on Industry Applications, Vol. 27, No. 2, pp. 245-253.

Rosenberg, E. 1917. Einseitiger magnetischer Zug in elektrischen Maschinen. Elektrotechnik und Maschinenbau, Vol. 35, No. 44, pp. 525-531, and No. 45, pp. 539-546.

Rosenberg, E. 1918. Magnetic pull in electric machines. Transactions of the American Institute of Electrical Engineers, Vol. 37, part 2, pp. 1425-1469.

Salon, S., DeBortoli, M., Burow, D. \& Slavik, C. 1992. Calculation of circulating current between parallel windings in induction motors with eccentric rotors by the finite element method. In: Proceedings of the International Conference on Electrical Machines 1992. Manchester, England, 15-17 September, 1992. Vol. 2. Pp. 371-375.

Skubov, D. Yu. \& Shumakovich, I. V. 1999. Stability of the rotor of an induction motor in the magnetic field of the current windings. Mechanics of solids, Vol. 34, No. 4, pp. 28-40 (Translated from Mekhanika Tverdogo Tela, 1999, No. 4, pp. 36-50)

Smith, A. C. \& Dorrell, D. G. 1996. Calculation and measurement of unbalanced magnetic pull in cage induction motors with eccentric rotors. Part 1: Analytical model. IEE Proceedings - Electric Power Applications, Vol. 143, No. 3. Pp. 193-201. 
Stoll, R. L. 1996. Simple computational model for calculating the unbalanced magnetic pull on a two-pole turbogenerator rotor due to eccentricity. IEE Proceedings - Electric Power Applications, Vol. 144, No. 4. Pp. 263-270.

Tenhunen, A. 2003. Electromagnetic forces acting between the stator and eccentric cage rotor. Espoo: Helsinki University of Technology. 40 p. (Laboratory of Electromechanics, Report series no. 69.) Available: http://lib.hut.fi/Diss/. ISBN 951-22-6682-2

Tenhunen, A., Benedetti, T., Holopainen T. P. \& Arkkio, A. 2003a. Electromagnetic forces in cage induction motors with rotor eccentricity. In: Proceedings of the IEEE International Electric Machines and Drives Conference. Madison, WI, USA, 1-4 June, 2003. Vol. 3. Pp. 1616-1622.

Tenhunen, A., Benedetti, T., Holopainen T. P. \& Arkkio, A. 2003b. Electromagnetic forces of the cage rotor in conical whirling motion. IEE Proceedings Electric Power Applications, Vol. 150, No. 5. Pp. 563-568.

Tenhunen, A., Holopainen T. P. \& Arkkio A. 2003c. Impulse method to calculate the frequency response of the electromagnetic forces on whirling cage rotors. IEE Proceedings - Electric Power Applications, Vol. 150, No. 6. Pp. 752-756.

Tenhunen, A., Holopainen T. P. \& Arkkio A. 2003d. Spatial linearity of unbalanced magnetic pull in induction motors during eccentric rotor motions. COMPEL: The International Journal for Computation and Mathematics in Electrical and Electronic Engineering, Vol. 22, No. 4, pp. 862-876. ISSN 0332-1649

Tenhunen, A., Holopainen T. P. \& Arkkio, A. 2003e. Effects of equalising currents on electromagnetic forces of whirling cage rotor. In: Proceedings of the IEEE International Electric Machines and Drives Conference. Madison, WI, USA, 1-4 June, 2003. Vol. 1. Pp. 257-263.

Tenhunen, A., Holopainen, T. P. \& Arkkio, A. 2004. Effects of saturation on the forces in induction motors with whirling cage rotor. IEEE Transactions on Magnetics, Vol. 40, No. 2, pp. 766-769. 
Tímár, P. L. (ed.) 1989. Noise and vibration of electrical machines. Amsterdam: Elsevier Science Publishers. 339 p. (Studies in electrical and electronic engineering 34) ISBN 0-444-98896-3

Toliyat, H. A., Arefeen, M. S. Parlos, A. G. 1996. A method for dynamic simulation of air-gap eccentricity in induction machines. IEEE Transactions on Industry Applications, Vol. 32, No. 4, pp. 910-918.

Wright, M. T., Gould, D. S. M. \& Middlemiss, J. J. 1982. The influence of unbalanced magnetic pull on the critical speed of flexible shaft induction machines. In: Proceedings of the International Conference on Electrical Machines-Design and Applications. London, 13-15 July, 1982. London: Institute of Electrical Engineers. Pp. 61-64. (IEE Conference Publication No. 213)

Yang, S. J. 1981. Low-noise electrical motors. Oxford: Oxford University Press. 101 p. ISBN 0-19-859332-5

Yang, B.-S., Son, B.-G. \& Lee, J.-W. 1999. Stability analysis of 2-pole induction motor rotor by unbalanced electromagnetic forces. In: Proceedings of the $10^{\text {th }}$ World Congress on the Theory of Machine and Mechanisms. Oulu, Finland, June 20-24, 1999. Pp. 1710-1715.

Yang, B.-S., Kim, Y.-H. \& Son, B.-G. 2004. Instability and imbalance response of large induction motor rotor by unbalanced magnetic pull. Journal of Vibration and Control, Vol. 10, No. 3, pp. 447-460.

Appendices III-VI of this publication are not included in the PDF version. Please order the printed version to get the complete publication (http://www.vtt.fi/inf/pdf) 


\title{
Author(s) \\ Holopainen, Timo P. \\ Electromechanical interaction in rotordynamics of cage induction motors
}

\begin{abstract}
Electromagnetic fields in the air gap of an electric machine produce electromagnetic forces between the rotor and stator. The total force exerted on the rotor due to the eccentric rotor position is called the unbalanced magnetic pull. This eccentricity force is directed roughly over the shortest air gap. At low frequencies, the vibration amplitudes of flexural modes may be large enough to couple the electromagnetic system to the mechanical one. This electromechanical interaction changes the vibration behaviour of the system.
\end{abstract}

The main purpose of this dissertation is to reveal the main rotordynamic consequences induced by the electromechanical interaction in cage induction motors. Another goal is to achieve this by deriving a simple and representative electromechanical rotor model with physical variables and parameters.

In this study, a new parametric model was derived for the unbalanced magnetic pull induced by an arbitrary rotor motion in transient operation. The parameters of this model can be determined analytically from the basis of the machine characteristics or estimated numerically as in this study. To estimate the parameters, an efficient numerical method was developed from the analysis of impulse response. The numerical results showed that the simple electromagnetic force model, together with the estimated parameters, predicts the unbalanced magnetic pull fairly accurately.

An electromechanical rotor model was derived by combining the Jeffcott rotor model with the simple electromagnetic force model, including two additional variables for the harmonic currents of the rotor cage. Applying this model, the rotordynamic effects of electromechanical interaction were studied. Three induction motors were used in the numerical examples. The results obtained show that the electromechanical interaction may decrease the flexural frequencies of the rotor, induce additional damping or cause rotordynamic instability. These interaction effects are most significant in motors operating at, or near, the first flexural critical speed. Excluding the potential rotordynamic instability, the numerical results indicate that the electromechanical interaction effectively reduces the unbalance response close to the first flexural critical speed.

\section{Keywords}

unbalanced magnetic pull, electromechanical interaction, rotors, electric motors, vibration characteristics

Activity unit

VTT Industrial Systems, Otakaari 7 B, P.O.Box 13022, FIN-02044 VTT, Finland

\section{ISBN}

951-38-6404-9 (soft back ed.)

951-38-6405-7 (URL:http://www.vtt.fi/inf/pdf/; URL: http://lib.hut.fi/Diss/)

\begin{tabular}{|c|c|c|c|}
\hline $\begin{array}{l}\text { Date } \\
\text { August } 2004\end{array}$ & $\begin{array}{l}\text { Language } \\
\text { English }\end{array}$ & $\begin{array}{l}\text { Pages } \\
64 \text { p. }+ \text { app. } 81 \text { p. }\end{array}$ & $\begin{array}{l}\text { Price } \\
\text { C }\end{array}$ \\
\hline \multicolumn{2}{|c|}{$\begin{array}{l}\text { Name of project } \\
\text { Electromechanical interaction in vibration control of } \\
\text { electric machines }\end{array}$} & \multicolumn{2}{|c|}{$\begin{array}{l}\text { Commissioned by } \\
\text { The National Technology Agency (Tekes), } \\
\text { VTT Industrial Systems }\end{array}$} \\
\hline \multicolumn{2}{|c|}{$\begin{array}{l}\text { Series title and ISSN } \\
\text { VTT Publications } \\
\text { 1235-0621 (soft back ed.) } \\
\text { 1455-0849 (URL: http://www.vtt.fi/inf/pdf/; } \\
\text { URL: http://lib.hut.fi/Diss/) }\end{array}$} & \multicolumn{2}{|c|}{$\begin{array}{l}\text { Sold by } \\
\text { VTT Information Service } \\
\text { P.O.Box 2000, FIN-02044 VTT, Finland } \\
\text { Phone internat. +35894564404 } \\
\text { Fax +3589456 } 4374\end{array}$} \\
\hline
\end{tabular}

